\title{
Unmoored, Unclaimed, Unsinkable: Interrogating Ideas of the Nation in Modern Taiwan
}

\author{
Aidan Lee \\ Distinguished Majors Program in History \\ University of Virginia
}

May 1, 2017 


\section{Acknowledgements}

This thesis would not have been written without the support of many people. I first want to thank Brian Balogh and Robert Stolz for their patience and guidance. I also thank Allan Megill, John R. Shepherd, Shirley Lin, Liu Xiaoyuan, and my peers in the Distinguished Majors Program for their generous assistance as I refined my topic. I am indebted to the family of David A. Harrison III for their generosity that made my research possible, and to the Gould and Nan family from Taipei and Nanwang who introduced me to the Puyuma community. Lastly, I am grateful for my friends, family, and Ruby Ho for the encouragement they've given me over the last few years. 
Lee 3

For My Grandparents 


\section{Table of Contents}

Illustrations 5

Introduction 6

Chapter 1 "Outside the Game": What is Post-National? .14

Chapter 2 Citizens Adrift: Wu Zuoliu's Orphan of Asia and the Ambivalence of Taiwanese Colonial Subjectivity 28

Chapter 3 Political Art, Impressionist History: Hou Hsiao-hsien's A City of Sadness and Taiwan's Nativist Literature Discourse

Chapter 4 Nostalgia Machine: Reconciling Past and Present in Wei Te-sheng's films

Conclusion 95

Bibliography 104 


\section{Illustrations}

Fig. 1. The Entrance to Ōgon Shrine 6

Fig. 2. The Remains of Ōgon Shrine $\ldots . .7$

Fig. 3. Taiwanese/Chinese Identification Trend Distribution in Taiwan (1992/o6 2016/12) .24

Fig. 4. Taiwan Independence vs. Unification with the Mainland Trend Distribution in Taiwan

(1996/o6 2016/12) 25 


\section{$\underline{\text { Introduction }}$}

Of information we have too much, and its production is exploding. Time to reflect and play.

-Hans Kellner, Ankersmit's Proposal: Let's Keep in Touch, 89

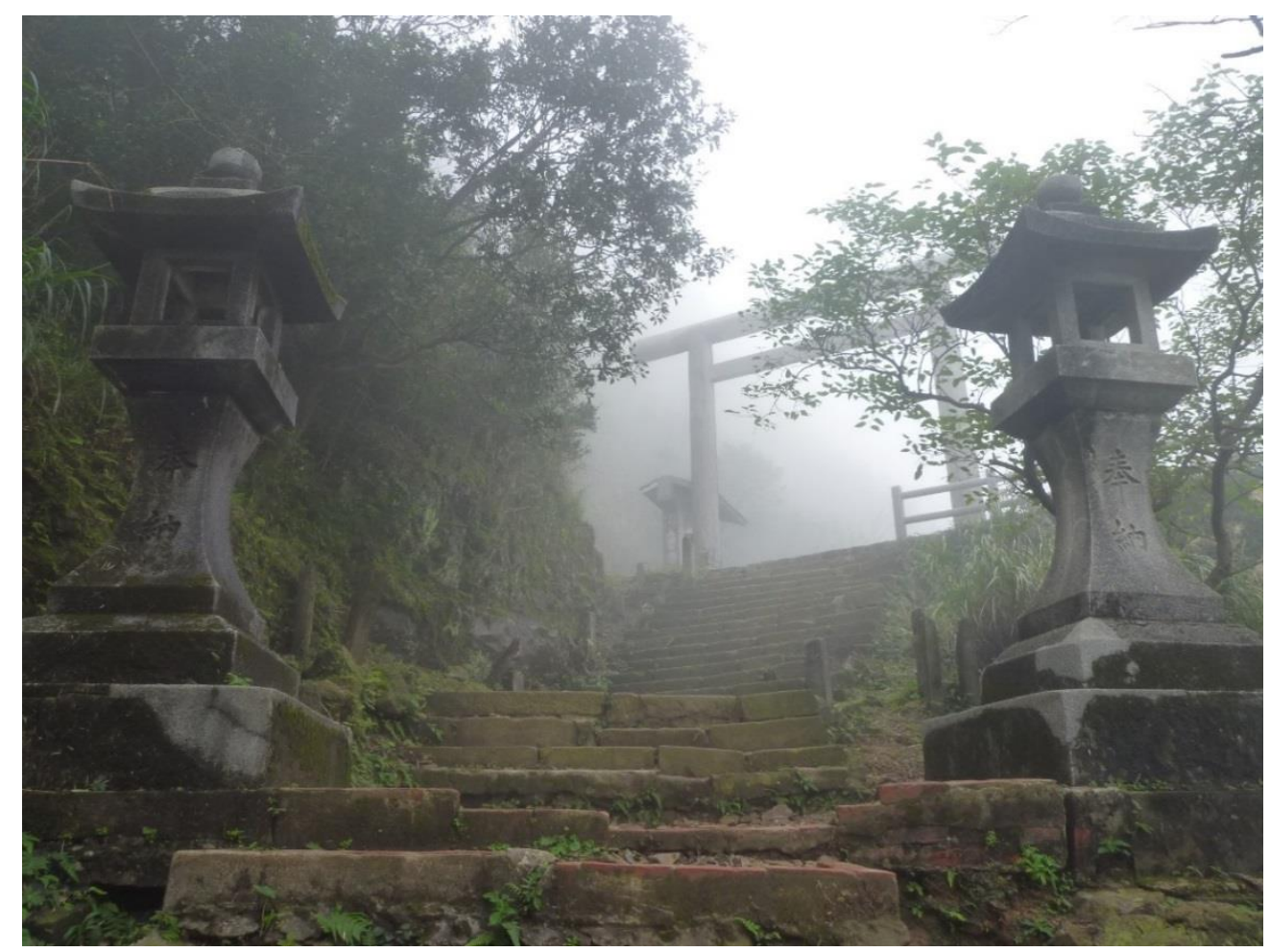

Fig 1. The entrance of an old Shinto shrine (Ōgon shrine) sits atop a stone stairway in the mountains overlooking Jiufen and Jinguashi, Taiwan. Photo by Author. Dec. 2016.

Nestled in the mountains of Rueifang District in New Taipei City lies the town of Jiufen. Seen on a quiet and misty morning, the town is shrouded in an almost mournful gloom; but Jiufen is transformed by nightfall under the lurid glare of lanterns, the aroma of delectable treats and the cacophonous din of humanity. The town is the setting of Ho Hsiao-hsien's 1989 blockbuster film City of Sadness, and has become a popular 
tourist location in recent years. Yet despite the jovial impression Jiufen exudes today, the town has a less than glamorous past. This was once a mining town that reached peak development during the Japanese colonial era, which spanned from 1895 to 1945 . The Japanese used nearby Jinguashi (Kinkaseki) to establish gold and copper mines, which were later adapted into forced labor camps for captured Allied soldiers in the early1940s. Now, Jinguashi is home to a gold museum replete with placards featuring sterile historical descriptions, brushed artifacts, and gift shops. However, should one stroll along the trails on the museum's periphery, one will find a series of winding stone steps, old rock foundations, and eventually the ghostly ruins of a Shinto shrine overlooking Jiufen and Jinguashi. Much like this monolith that lies forgotten in the heart of overgrown foliage, the cultural memories of the Japanese era lie embedded in the people of Taiwan, whether dormant or acknowledged, and are a key ingredient in modern Taiwanese cultural identity and imagination. 
Fig. 2. The remains of Ōgon Shrine are a popular tourist location today, as they are a short hike away from the Jinguashi Gold Mine Museum. Photo by Author. December 2016.

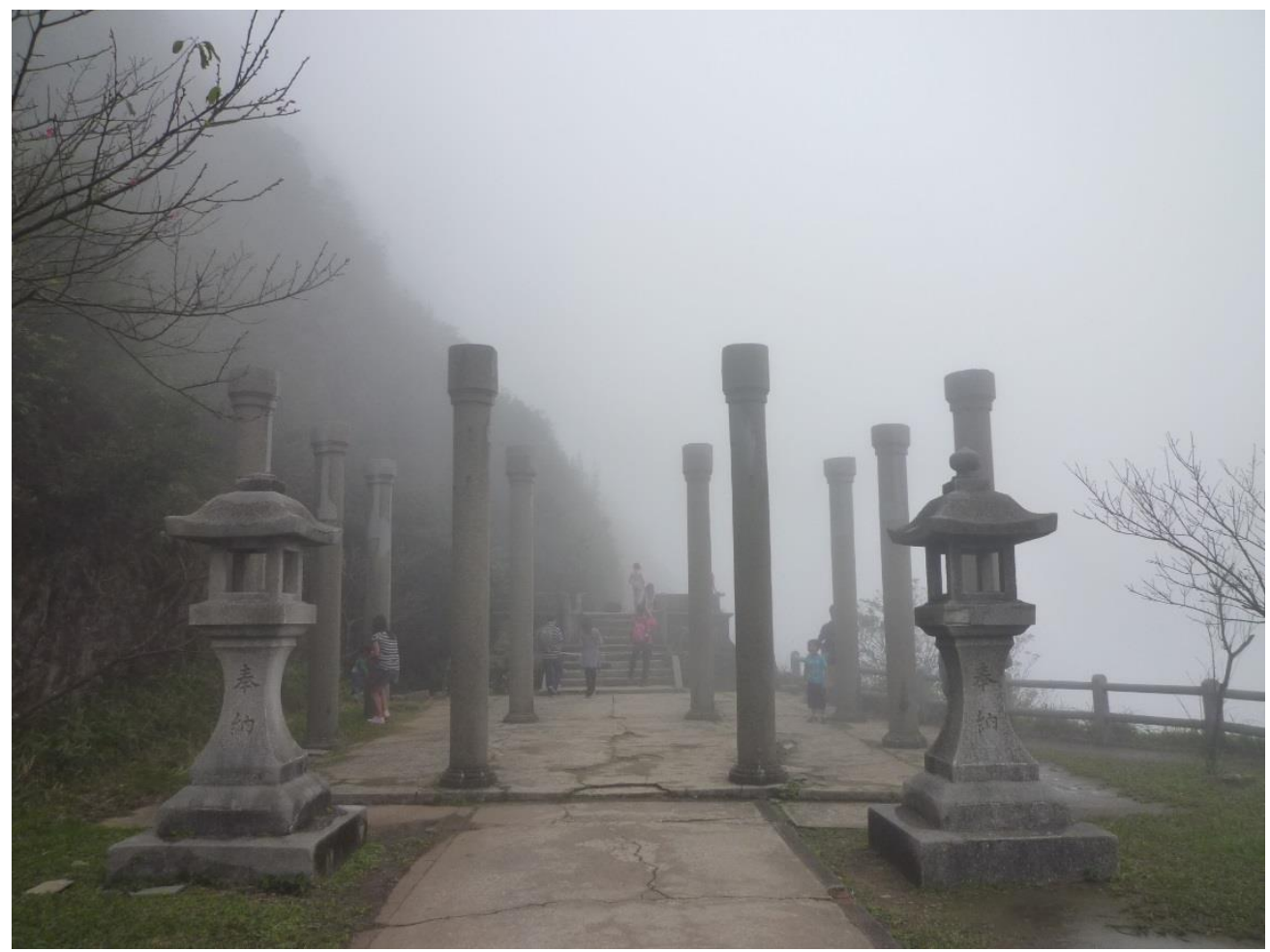

For more than half a century, the People's Republic of China has claimed that Taiwan is a rogue province of China, and has sought to unify Taiwan politically with the mainland. A significant obstacle stands in the way of this so-called "re-unification": as of recent decades, the vast majority of Taiwanese do not identify solely as "Han-Chinese." The assumption of a shared ethnic-Chinese identity is the crux of China's argument for re-unification, and yet it is mistaken in its simplistic understanding of Taiwanese identity. ${ }^{1}$ Although it is true that the majority of Taiwan's population are descended from the Han ethnic group, and that these people retain many Han cultural traditions (visible in family and social structure, folk religion, language and dialect), the CCP's usage of the term Zhonghua in relation to Taiwan remains a crude simplification, as

${ }^{1}$ Melissa J. Brown, Is Taiwan Chinese?: the impact of culture, power, and migration on changing identities. (Berkeley: Univ. of California Press), 2008. 22. 
cultural-national identity is not limited solely by linguistic or religious parameters. ${ }^{2}$ Zhonghua represents, in this context, a political and rhetorical weapon intended to achieve the ends of unification, rather than an accurate historical or conceptual framework. This thesis provides an alternative framework that sheds some light on a contentious and difficult aspect of Taiwan's history, while avoiding traditional crossstrait political biases that have influenced many scholars' work.

Modern Taiwanese history, from 1895 to present, has been marked by a series of significant cultural "interruptions." For half the century, Taiwan was a Japanese territory, and for most of the second half, an officially "Chinese" territory. By the first decades of the twenty-first century, however, even the most hardline Chinese Nationalists of the Kuomintang have given up the prospect of re-conquering China. At this time, people in Taiwan also gradually began to identify more as "Taiwanese" than "Chinese."3

Taiwan is recognized today as a country that is a de facto but not de jure nationstate. There is no international political consensus on the issue of Taiwan's nationhood and identity, due in large part to the PRC's insistence on the "One China" policy. Among historians there is also an awareness of the close ties between the political nation-state and the corresponding cultural history and identities that define it. The historical literature on Taiwan reflects this quandary to a degree; thus most political histories conclude with the unresolved relationship between China and Taiwan, but rarely

${ }^{2}$ Zhonghua is used to signify "the Chinese Nation" or "Chinese Civilization" 3 According to polling data from National Chengchi University. For more, see Fig. 3 and Fig. 4 (20-21). Also See Shirley Lin, Taiwan's China Dilemma: Contested Identities and Multiple Interests in Taiwan's Cross-strait Economic Policy (Stanford University Press: 2016), 54-56. 
provide an incisive and definitive comment on who or what, exactly, present-day people living in Taiwan perceive themselves to be in cultural and national terms. ${ }^{4}$

Growing up in Taiwan, I have long been aware of the important roles Taiwan's two most recent colonial regimes have in the discourse surrounding modern Taiwanese nationhood today. This led me to the following questions that guide this thesis. Did representations of colonial Taiwanese life in popular historical films and novels differ before and after democratization (1996)? And to what extent did they reveal a notion(s) of Taiwanese identity?

I offer an interpretation of present day Taiwanese identity ("Taiwaneseness") via an examination of narrative representations of colonial life and of the modern contexts in which these representations proliferated. 5 My analysis centers on four popular works of historical fiction: Wu Zuoliu's autobiographical novel Orphan of Asia (1946), Hou Hsiao-hsien's film A City of Sadness (1989), and Wei Te-sheng's films Cape No. 7 (2008) and Seediq Bale (2013). I choose Orphan and City as my pre-democratization sources because they occupy an important place in Taiwan's colonial literature and "resistance" genres. I chose Cape No. 7 and Seediq Bale as post-democratization sources because they remain Taiwan's two top-grossing domestic films, and use Taiwan's Japanese past as settings and/or as central subject matter.

\footnotetext{
4 Such historians as John F. Copper and Murray Rubinstein, for example. Leo T.S. Ching and Anthropologist Melissa Brown provide a good starting point for my purposes due to their intricate historical treatment of the complex Taiwanese identity, but I am taking a different approach. 5 Melissa Brown, in Is Taiwan Chinese? characterizes national and ethnic identity as "socially constructed" in the sense that it is shaped by everyday experiences and interactions. Parts of her work dealing with changes in Aborigine-Han identity therefore focuses heavily on the environments created by public policies during the Japanese era. I wish to explore how a society reflects upon its past and present, and renegotiates its understanding of the past through art.
} 
In 1996, after decades of inherited rule by Chiang Kai-shek and his son Chiang Ching-kuo, Taiwan held its first popular elections under President Lee Teng-hui. Lee had served for eight years during the transition period following President Chiang Ching-kuo's death in 1988. Before and after democratization, popular historical films and novels centered on Taiwan's colonial Japanese (1895-1945) and semi-colonial Kuomintang eras (1945-1987) show very different interpretations of life in Taiwan, and what it means to be "Taiwanese." I argue, however, that these representations do express a "nationalism" in the traditional sense, but instead display a "post-national" character in their rejection of a common cultural origin, common set of colonial relations, or binding set of ideals and values.

The pre-democracy works (along with Wu's memoir, The Fig Tree, published in 1970) depict native-born Taiwanese as caught in a cultural double bind between "China" and "Japan," and as people who are disillusioned with outsider-run governments, yet unable to shake off the paralyzing confusion that attends the circumstances of colonial life (i.e., to resist, or assimilate?). The post-democracy works build off the conceptual foundation of the people of Taiwan as one without a national identity clearly demarcated from its colonial hegemons. By rejecting the traditional historical perspectives of the dominant "Chinese" ethnicity in favor of native-born Taiwanese (including Hakka, and aboriginal peoples), these films provide an alternative way of viewing Taiwan: as home to a multiplicity of identities. Because this idea of Taiwan opposes ethnic-essentialism, I see it as form of "anti-nation-building." The post-national elements present in popular Taiwanese historical fiction suggest the limits of the nationstate conceptualization in cultural discourse. 
I take inspiration from Hayden White, a scholar of history and literary criticism, in my emphasis on the profound importance of different interpretations of history in popular historical fiction. White argues that historical writing is valuable not when it seeks to become as objective or methodologically "scientific" as possible, but when it embraces "narrativity."6 He develops this point in The Practical Past, where he argues for an understanding of (good) historical representation as necessarily poetic, or "literary," and for a broadening of what we consider historical knowledge. This broadening, he implies, should take into account both the important relation between historical narrative and "fiction," and the significance of the past for us in the present.7 I also draw from Frank Ankersmit, another "Narrativist" philosopher of history, whose discussion of art and "historical representation" contributes to my analysis of A City of Sadness in Chapter Three.

That the works I analyze are all "historical" (in the sense of dealing with either the past, or with the lingering effects of the past in the present) is significant. Predemocracy historical fiction largely defines "Taiwaneseness" negatively, against Chinese and Japanese imperial identities, by emphasizing the failure of assimilation symbolized by the destruction of the family. Though this carries on somewhat into the $21^{\text {st }}$ century in films like Seediq Bale, there is overall a deeper emphasis on the fragmented identities (perhaps even "nations") within Taiwan. The popularity of all these works, especially the recent films Cape and Seediq, indicates the close ties between the contemporary political climate and aesthetics, identity, and history.

\footnotetext{
${ }^{6}$ Hayden White, "The Value of Narrativity in the Representation of Reality," Critical Inquiry, Vol. 7 No.1 (Autumn 1980): 5-27

7 See Hayden White, The Practical Past, (Evanston, IL: Northwestern University Press, 2014)
} 
A comparison of these works with respect to their treatment of Japanese (and to a lesser extent Chinese) imperialism leads me to conclude that the limits of the nationstate conception cannot fully account for Taiwanese cultural and political complexity. I believe that these works highlight the "post-national" character of contemporary Taiwan because they show that "nation" cannot encompass and account for disparate localities/communities and ethnicities within the single state that is Taiwan. Each work interprets Taiwan's colonial relations differently, and taken as a whole they show both the impossibility of tracing a "national origin" or national consciousness in Taiwan, and the inevitability of multifarious communities and cultural identities within a single state. They do not represent a "Taiwanese Nation" because they do not offer up a common set of binding factors that unite "Taiwanese." Rather, they are portraits of individuals and groups within a common space, whose worlds intersected, but who were not necessarily united in their understanding of identity or even in the pursuit of goals like political autonomy or representation within (or against) the state.

This argument is articulated across four chapters. In Chapter One, I outline Etienne Balibar and Immanuel Wallerstein's theories of nation and identity, and justify my use of the "post-national" category. In Chapter Two I analyze Orphan of Asia and Wu Zhuoliu's 1970 memoir, The Fig Tree, before moving on to A City of Sadness and a discussion of Taiwan's heated "Nativist Literature debate" of the 1970s-80s in Chapter Three. In Chapter Four I compare Cape No. 7 with Seediq Bale, and consider the significance of their themes in relation to present-day Taiwan. 


\section{Chapter One}

\section{"Outside The Game": What is Post-National?}

Before I discuss the post-national with regard to historical fictions and the contexts of their creation, some definitions are necessary. Exactly what conceptions of "nation" or "identity" do I have in mind when I propose that these works inculcate a post-national character? I begin by introducing Etienne Balibar and Immanuel Wallerstein's theories on nation and identity.

In a collection of essays titled Race, Nation, Class: Ambiguous Identities, Balibar and Wallerstein propose several ways of viewing the nation-state system that was historically a competitor with (and now perceived "successor" to) the system of empire. Wallerstein argues that generally, sovereign states that are today recognized and identify as "nations" were frequently threatened by "internal disintegration and external aggression." 8 These threats were lessened by the development of "national sentiment," which occurs in the state's interest because it legitimizes state claims on one hand, and supports administrative uniformity that increases the efficacy of policies. ${ }^{9}$ Nationalism is thus the expression, promoter, and consequence of state-level uniformities. Following this logic, Wallerstein explains that the interstate system in general is not a mere collection of "so-called sovereign states," but a hierarchical system with a "stable (but

\footnotetext{
8 Etienne Balibar and Immanuel Wallerstien, Race, Nation, Class: Ambiguous Identities, Radical Thinkers (Verso: 2011), 81

${ }^{9}$ Balibar, Race Nation Class, 82
} 
changeable) pecking order." Therefore, "for a state not to be a nation is for that state to be outside the game of either resisting or promoting the alteration of its rank."10

In his critique of modern nation states, Balibar says that he is inspired by a fundamental contradiction in the notion of modern states: that states are generally conceived of today as "nation-states, or national states," but on the other hand there is also a clear recognition among scholars that there is an "imperfect match between the 'state' and the 'nation."'11 In other words, states tend to become nations (historically speaking), but "nations" do not always form states, or at least states which cover all of a nation's "sociological aspects."12

Balibar contends that historical representations of nations in general portray nations as the culmination of successive (or attempts at) state formations. Correlatively, it was by becoming "national" that states transformed themselves into what are now recognized as "modern states." These modern states have their own ideologies and collective sovereignties, juridical and administrative rationalities, and (perhaps most importantly) particular modes of regulating social conflict, and strategic management of resources and territory with the aim of maximizing economic and military power. The existence of nation-states is always one of balance, Balibar contends, between two opposing aspects. The idea of "nations without a state, or nations 'before' a state," is thus a "contradiction in terms, because a state is always implied in the historical framework of national formation." 13

\footnotetext{
${ }^{10}$ Balibar, Race Nation Class, 82

${ }^{11}$ Etienne Balibar and Immanuel Wallerstein, Historiography: Critical Concepts in Historical Studies, trans. Chris Turner. Ed. Robert M. Burns (Routledge, London and New York: 2006), 45

${ }^{12}$ Balibar, Race Nation Class, 45

${ }^{13}$ Balibar, Race Nation Class, 45
} 
However, this paradox of national states is often shrouded in myth. Because of the inevitable regional, class or other social divisions that occur within a nation-state, it projects beneath its "political existence” an underlying 'ethnic' or 'popular' unity (into the past, into the depths of 'civil society')." A state or other historical collective may, in the struggle against other states, "justify its claims to autonomy by drawing an ideal trajectory from a more or less mythical origin (linguistic, religious, cultural, racial) toward an end considered to be the only historically normal possibility, the creation of its own national-state structure."14

According to Balibar, representations of nations rely on a two-fold illusion: first, the belief that "generations which succeed one another over centuries on a reasonably stable territory, under a reasonably univocal designation, have handed down to each other an invariant substance." Second, in their retroactive selection of aspects from a perceived "process of (national) development," members of nation-states tend to see themselves as the necessary culminations of that process, which represents a destiny of sorts. 15 The way "national" histories are presented, then, make nations appear to be the "fulfillments" of "projects" that stretch over centuries, "in which there are different stages and moments of coming to self-awareness, which the prejudices of various historians will portray as more or less decisive."16 Moreover, "the myth or origins and national continuity" necessary for the imagining of nation-states, old and new, is according to Balibar an "effective ideological form, in which the imaginary singularity of

\footnotetext{
${ }^{14}$ Balibar, Race Nation Class, 46

${ }^{15}$ Balibar, Race Nation Class, 86

${ }^{16}$ Balibar, Race Nation Class, 86
} 
national formations is constructed daily, by moving back from the present into the past."17

Balibar concludes that no nations possess "natural ethnicities," so that national unity thus relies largely on "fictive" ethnicities that are formed out of "ethnicized" populations within nationalizing states. ${ }^{18}$ Fictive ethnicity is formed through two competing routes (though in most nations, also complementary): language and race. Common to both, however, is the notion that "national character" is immanent in the people. With regard to language, Balibar suggests that social differences are expressed and relativized as different ways of speaking the national language."19 Therefore, the institution of the school is of crucial importance to the nation-state: it normalizes in citizens a specific worldview, as well as shared interests and cultural history, by inculcating in citizens a common national language. The language community "produces the feeling that it has always existed," but lays down no destiny for successive generations. It “'assimilates' anyone, but holds no one." Because of this, it is generally held within the boundary of a state with the complementary and exclusive principle of race. Balibar holds that the "symbolic kernel" of the idea of race is the "schema of genealogy," or the idea that the "filiation of individuals transmits" across generations "a substance both biological and spiritual" thereby inscribing them in a "temporal community known as 'kinship'.”2o

Although Balibar recognizes that the competing elements are hardly particular to nation-states (i.e., empires), he argues that the difference of a "national" kinship is the

\footnotetext{
${ }^{17}$ Balibar, Race Nation Class, 87

${ }^{18}$ Balibar, Race Nation Class, 96

${ }^{19}$ Balibar, Race Nation Class, 97

${ }^{20}$ Balibar, Race Nation Class, 100
} 
dissolution of private genealogies (of clan, for example), in favor of treating the nation itself as an extended "clan" whereby marriage between any two individuals within the nation-state may be normalized. It is now the state that "draws up and keeps the archives of filliations and alliances.”21 Before connecting Balibar's fictive ethnicities to my topic, I first turn to Melissa J. Brown's book, Is Taiwan Chinese? The impact of Culture, Power, and Migration on Changing Identities, to problematize the idea of a "Han-Chinese" ethnicity and identity formation in Taiwan. Brown points out that from a historical-anthropological standpoint, the "Han-Chinese" of Taiwan are not an ethnic/linguistic/cultural monolith, and instead speak a variety of dialects, and have a long history of intermarriage with aboriginal groups in Taiwan.

\section{Who Are The "Han-Chinese"?}

Brown points out that, over the course of several hundred years (from the $16^{\text {th }}$ century), aborigine villages in western Taiwan gradually became "Sinicized" as male Han settlers migrated and married into them. Because of the patrilineal Han lineage system, aboriginal villages "turned" at the point at which the "density of Chinese settlers was such that people no longer perceived Chinese men in an aborigine village and instead began to perceive a Chinese community with aborigines in it."22 Brown discusses identity formation in relation to Taiwan. She argues that identity formation "is the process of socially negotiating how to classify oneself in terms of the broader classifications of people existing in a particular social and cultural context." 23 Specifically, she proposes fellow anthropologist Dan Sperber's thesis, that human

\footnotetext{
${ }^{21}$ Balibar, Race Nation Class, 101

${ }^{22}$ Melissa J. Brown, Is Taiwan Chinese?, 16

${ }^{23}$ Melissa J. Brown, Is Taiwan Chinese?, 13
} 
cognitive processes encourage "essentializing classifications," and that cultural input which classifies people can be construed in the brain as signifying a larger, more essential distinction. ${ }^{24}$ The language of classification itself then seems to have a significant impact on individual perception of ethnic identity.

On this basis, Brown suggests that despite the official Kominka ("imperialization," see Chapter Two) policy that sought to instill loyalty to Japan, people in 1930s-40s Taiwan still experienced "clear categorical differences between themselves and Japanese.”25 Brown explains that this was a result of Japanese household registers, which categorized people in Taiwan according to "race," and linguistic differences even among Han-Chinese (such as the Hoklo and Hakka peoples, who spoke mutually unintelligible dialects). Further, distinctions were made between "cooked” (plains dwelling, pingpu) and "raw" (mountain dwelling) aborigines. The former were gradually recognized on nearer footing with Hoklo Han-Chinese because they adopted more Han customs and language, and intermarried more often with Han, while the latter were brought forcibly under control. Japanese classification system not only perpetuated measures taken by the Qing regime, but became more extensive over time. By the latter half of Japanese rule in Taiwan, authorities became more concerned with distinguishing between class differences, and between Japanese and native Taiwanese. ${ }^{26}$ Seediq's historical representation engages with these ideas of essential difference, but rejects them. Wei's film works to "humanize" both sides of the conflict, and instead points out similarities between the two groups despite prioritizing the Seediq perspective over the Japanese.

\footnotetext{
${ }^{24}$ Melissa J. Brown, Is Taiwan Chinese?, 15

${ }^{25}$ Melissa J. Brown, Is Taiwan Chinese?, 9

${ }^{26}$ Melissa J. Brown, Is Taiwan Chinese?, 8-9
} 
Because she views identity as "fluid," Brown thus contends that "Taiwanese identity" can thus be identified ethnically as an amalgamation of Han and Aborigine ancestry. ${ }^{27}$ With the exception of the more hostile and secluded mountain aborigines in Central Taiwan, the "Pingpu" or plains aborigines and Han settlers had intermarried and coexisted for hundreds of years prior to the arrival of the Japanese. The interesting feature of the Taiwanese population in this regard, claims Brown, is that aborigine cultural contributions and matrilineal ancestral traditions are both sufficiently present to make Taiwanese different from Chinese, and yet sufficiently hidden to allow Taiwanese to claim continuity with narratives of "Han culture." 28 Brown points out that to this day, "Han ethnic identity and Chinese national identity are conflated by people within China [...] and by academics within and outside of China."29 The term, once used by the Kuomintang (and now by the PRC) zhonghua minzu (roughly "Han-Civilization") exemplifies this erroneous conflation.

Brown argues against another assumption, that Han culture is fundamentally linked to a "Chinese national identity," with Han culture as sharing common roots in writing, political systems, patrilineal ancestor worship, and ritualized hierarchical relations ( $l i$, 禮), ostensibly features of “Han civilizations" dating back to the Xia and Shang Dynasties. Brown relates the complex idea of a Han ethnic identity by asserting that "Confucian culturalism" is a link between Han ethnic identity and specific cultural practices. In contrast to Japanese ideologies regarding colonized peoples in the 1920s40s as inherently, genetically (and irreconcilably) different, Brown posits that Confucian culturalism as an intellectual framework suggested that peoples could be considered

${ }_{27}$ Melissa J. Brown, Is Taiwan Chinese?, 13

${ }^{28}$ Ibid., 21

29 Ibid., 22 
Han as a result of "cultural practices regardless of their ancestry." To Confucians, argues historian Patricia Ebrey, the Han Chinese systems of social organization and morality were both superior, and universally applicable in the sense that they did not erect barriers against absorption of outsiders, and saw expansion of China through transformation and assimilation of non-Chinese as a "natural state of affairs."30 Therefore, it seems that the Taiwanese Han-dominant cultural tradition was inherently more "fluid" than the corresponding Japanese ideologies, despite the fact that it was the Japanese colonial government which nominally sought to 'assimilate' another group. The inherent fixedness of the Japanese in this regard, reinforced by the self-image of "homogeneity" and the historical idea of Japan as a sacred territory meant for those of Japanese ancestry, thus presented a profound obstacle for Taiwanese. Taiwanese subjects could not fully realize themselves ontologically and culturally as Japanese, despite being able to embrace the material benefits (and appearances) that Japan provided.

Balibar implies that the methods by which nations and "fictive ethnicities" are constructed, and the way they are perceived by their constituents, rely on a Hegelian teleology. The two most important conditions of this worldview for the purposes of a nation-project are that, first, the past is irrevocable, and second, that there are immaterial "essences" of things that are preserved in (and transferred across) historical time. The Hegelian worldview manifests itself in interesting ways in the arguments of scholars and artists that deal with the issue of Taiwan's nationhood. For example, in 
Chapter Three I discuss Taiwan's Nativist Literature debate of the 1970s, and show that some prominent pro-(Taiwan) independence advocates suggested that truly "Taiwanese" art could only come from native-born Taiwanese, as opposed to emigres from the mainland. So-called nativist art also had to deal with the "land and soil" (hsiang-tu) and the lives of Taiwanese of lower-socio economic status, which prompted the Kuomintang authorities to belittle it for its allegedly communist undertones. On the other hand, prounification scholars argued that Taiwanese literature should be conceptually subsumed under a greater category of "Chinese literature." The Kuomintang, for example, styled itself as a "Chinese" party, and promoted the use of classical/archaic writing styles and continued use of traditional Chinese characters after it retreated from the mainland after the Chinese Civil War in 1949, to differentiate itself from the CCP and legitimate its claim as the "real" China. ${ }^{31}$ Of course, no consensus was reached, because such narrow descriptions of "Taiwanese art" could never account for the great variety of later work that dealt with other aspects of life in Taiwan, such as films and literature centered on (increasingly) urban Taiwanese life, as well as LGBTQ, aboriginal, feminist, and mainland émigré art.

Notions of "Taiwanese art" are inextricably tied to Taiwan's political circumstances in the latter half of the twentieth century, and by extension the murky circumstances of Taiwan's nationhood. Because of Taiwan's economic successes under the Kuomintang, and the successful transition to democracy in 1996, the Kuomintang's

${ }^{31}$ Yvonne Chang, Modernism and the Nativist Resistance (Duke University Press: Durham and London, 1993), 24. The Kuomintang government also preserved many important Chinese artifacts that it brought to Taiwan after evacuating the mainland, many of which are kept in the National Palace museum. This contributes to the Kuomintang's positive legacy because this act of "cultural preservation" likely saved many historical artifacts from destruction by the Communists in the course of the Cultural Revolution (1966-76). 
legacy today is not completely negative, and it is not remembered solely for oppressive martial law. There is ambivalence in Taiwan, however, toward the "Chineseness" that the Kuomintang state and party styled itself on. According to polling data gathered over the last two decades, most of Taiwan's population, and even some in the Kuomintang itself, have begun to change their "identifications" from strictly "Chinese" to "both Chinese and Taiwanese," with the solely "Taiwanese" option gaining more popularity in recent years. ${ }^{2}$

${ }^{32}$ Shirley Lin, Taiwan's China Dilemma, 54-56. See Fig. 2. and Fig. 3. 
Fig. 2. Election Study Center. Taiwanese/Chinese Identification Trend Distribution in Taiwan (1992/o6 2016/12). Important Political Attitude Trend Distribution. National Chengchi University: http://esc.nccu.edu.tw/course/news.php?Sn=166\#

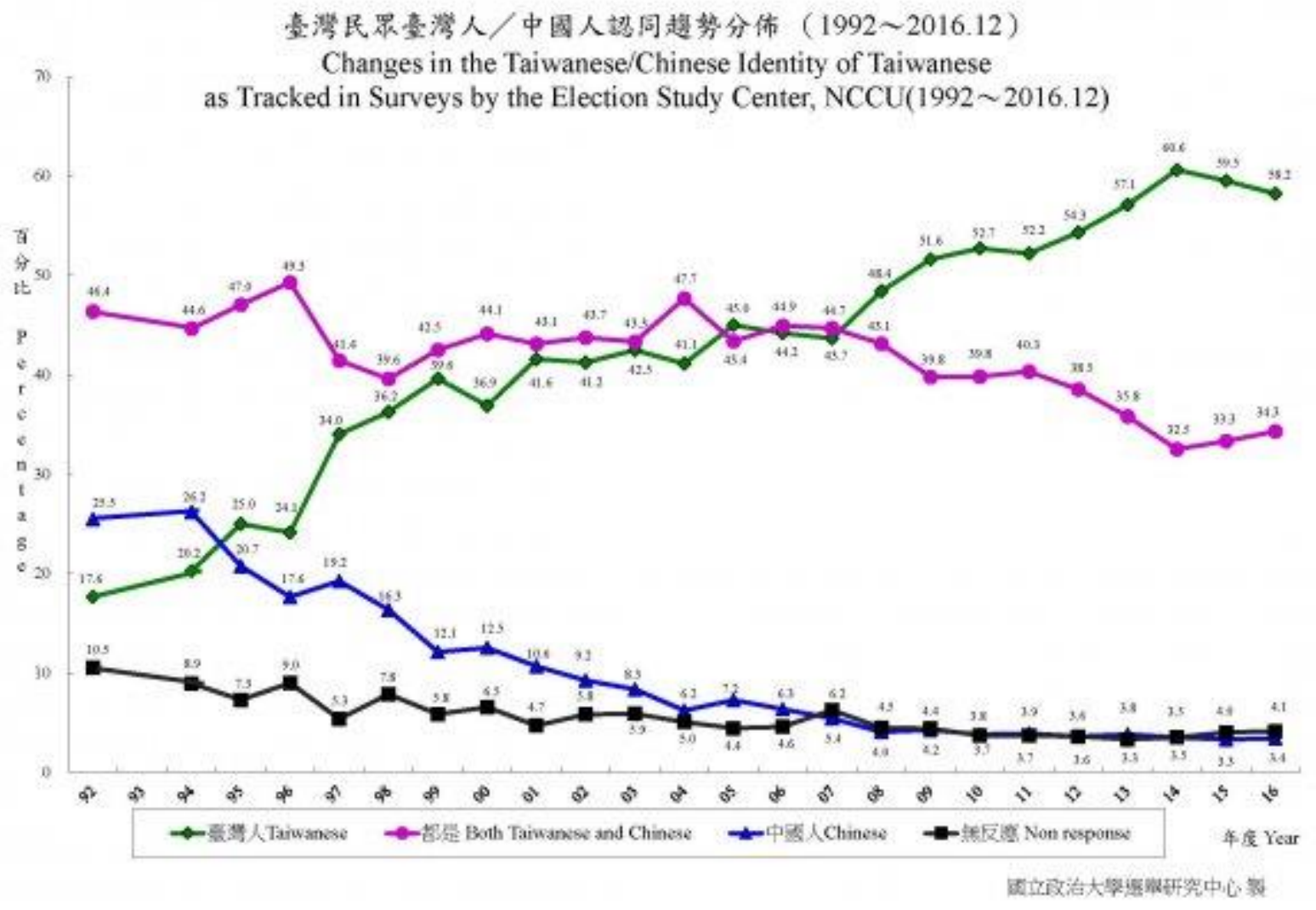


Fig. 3. Election Study Center, Taiwan Independence Vs. Unification with the Mainland Trend Distribution in Taiwan (1996/o6 2016/12). Important Political Attitude Trend Distribution. National Chengchi University: http://esc.nccu.edu.tw/course/news.php?Sn=167\#

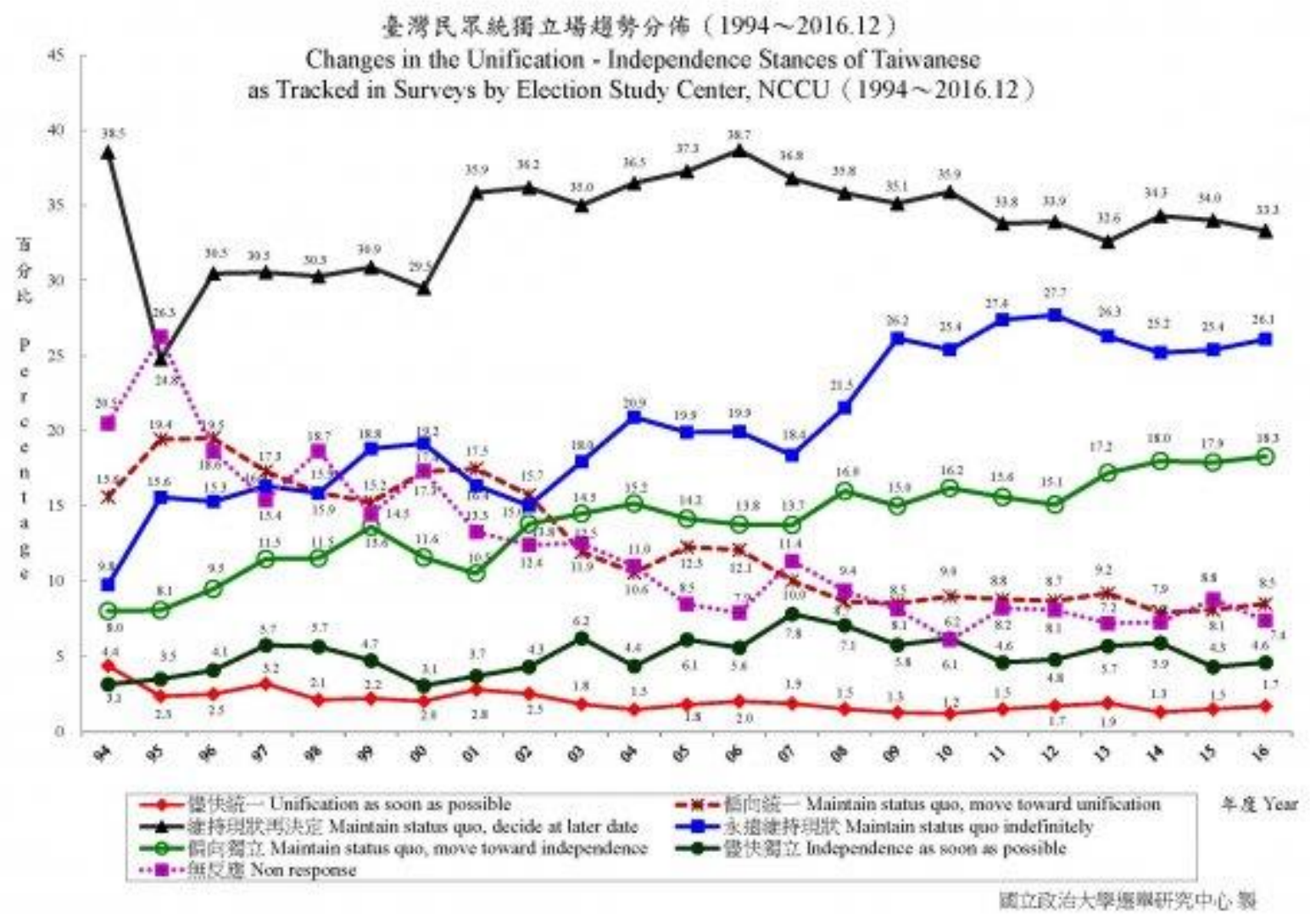

Therefore, I think the inconclusiveness of the Nativist debate suggests the dangers of an essentialist/Hegelian worldview in our consideration of Taiwan. I believe this inconclusiveness also hints at the limits of the "national" as an adequate concept in our consideration of history-oriented art in Taiwan. I do not believe these works of popular historical fiction promote, explicitly or implicitly, the notion of an independent Taiwanese nation. In fact, they consistently undermine the concept of "nation" and the idea that a Taiwanese nation formed over time. Whereas the literary debate of the 1970 s was motivated by political independence/unification, and sought to define "essential" characteristics of Taiwanese life and national identity, my analysis of these works 
instead shows the impossibility of a unified Taiwanese experience or binding values. Rather, the works retreat from the "universal" into portraits of the "particular," by highlighting regional historical experiences, individual experiences, and a plethora of distinct ethnic and linguistic identities within Taiwan.

By "post-national" I mean to signify that the common mentality that binds these works is one that situates their characters somewhere "outside the game" (of nationhood), to use Balibar's phrase. Although "non-national" is also accurate, I think they are more appropriately called "post-national" because they reflect on and critique the historical contexts they take as settings and subject matter (Taiwan's colonial Japanese and semi-colonial Kuomintang years) with relation to Taiwan's ambiguous status as a nation. By using "post-national" I am not suggesting that Taiwan had somehow become a nation at some point and moved on; rather, the Taiwan state transitioned from being a part of the Japanese empire, to be unofficially "adopted" by the Chinese Nationalists, another foreign government, to finally a popular democracy in 1996 through a peaceful process. Empire, as Balibar and Wallerstein suggested, acted as a kind of alternative state-system before national states became the predominant form. Therefore, I believe it is accurate to characterize post-Japanese Taiwan as "outside the game" of nations, a country and state that never fully was able to assert itself internationally and domestically as a proper nation-state. The works I analyze continuously construct experiences and portraits of Taiwan's people under imperial systems, and highlight the connections such past experiences have to the author's and directors' present. 
The works all, to an extent, belong under the post-colonial genre, though some inhabit a more confusing space. Orphan of Asia, for example, is a critique of Japanese imperialism, but Wu's later autobiography (The Fig Tree) also characterized the Kuomintang era as imperialistic and similar to the Japanese regime in certain respects. Orphan of Asia is thus post-colonial from one perspective, but "colonial literature" from another. Ultimately, I opted for "post-national" (or non/anti-national) because "postcolonial" is not decisive enough a signifier in the context of a thesis that deals with historical representation and national identity. With this framework in mind, I begin my analysis in the following chapter with a discussion of Wu Zhuoliu's novel Orphan of Asia (1946), which is set in Taiwan's Japanese era (1895-1945). 


\section{Chapter Two}

\section{Citizens Adrift: Wu Zuoliu's Orphan of Asia and the Ambivalence of Taiwanese Colonial Subjectivity}

Wu Zuoliu (1900-1976) was a Taiwanese journalist, novelist, and poet of Hakka descent. Wu's best known work is Orphan of Asia, a semi-autobiographical novel written in the final months of the Pacific War in 1945, and published in 1946, originally in Japanese. The book underwent several title changes over the ensuing decades, and was translated into Chinese in 1962. Orphan of Asia is important to my project because it was published at a key moment in Taiwanese history: the interregnum between two colonial regimes. Leo T.S. Ching, a historian of the Japanese Empire, notes that the Wu's treatment of the "ambivalent and equivocal relationship" between Taiwan and mainland China made Orphan "quite useful ... [both] for those who favor the eventual reunification with mainland China and those who advocate for Taiwanese independence." 33 The novel drew interpretations from such ideologically opposed writers as Chen Ying-zhen and Song Tse-lai. Chen, arguing from the premise that Taiwan was an "integral part" of China, saw Orphan as suggestive of a common TaiwanChinese nationalism, united in resistance against imperialism. According to Chen, $\mathrm{Wu}$ "recorded in his works the anti-imperialist will and spirit of the Chinese people."34 Song's reading, on the other hand, was influenced by his motivation to locate an autonomous Taiwan. Song suggested that the pitiful depiction of the Taiwanese as

33 Leo T. S. Ching, Becoming "Japanese": colonial Taiwan and the politics of identity formation. (University of California Press: Berkeley, 2001), 180 34 Chen Ying-zhen, "Shih-pin 'ya-his-ya de ku-er' [On 'The Orphan of Asia']” Tai-wan wen-I [Taiwan Literary] (Taipei: 1978), 256 
"orphaned" and "insulted and misunderstood" wherever he went, was in fact the "first true self-portrayal" of the people of Taiwan (and representative of "Taiwanese consciousness"). 35

Wu's work posed a set of problems in 1945 that have influenced a wide array of scholars concerned with Taiwanese identity and consciousness, and that continue to extend into present-day discourse on Taiwan. What defines life in Taiwan? Who are the "Taiwanese" and do they occupy a distinct space outside of Japanese and Chinese spheres of influence? In this chapter, I discuss Wu's depiction of colonial life in Taiwan under the Japanese both in his novel and in his autobiography, The Fig Tree.

Writing Orphan of Asia was an act of cultural protest. In The Fig Tree, serialized first in 1968 in the Taiwan Literature magazine and published separately in 1970, Wu recounted the danger of writing the text in Taiwan under Japanese rule:

The fourth and fifth chapters were written under dangerous circumstances. If discovered, I would be labeled an anti-war supporter (pacifist) and dealt with accordingly. In order to avoid such dangers, I decided to hide my work in a coal basket as soon as I had finished two or three pages, and once I had written a sizeable amount, would take it back home to the countryside to hide it. Even then I could not fully relax. Opposite my living quarters were the residences of the Colonial Police Department, and I knew a few of the officers well. Even under such precarious circumstances, I still managed to finish the novel six months before hostilities ceased. 36

\footnotetext{
35 Emphasis mine. I discuss “Taiwanese consciousness" later in this chapter. For more on the novel's reception, and on colonial and post-colonial Taiwanese literature in general, see Leo T.S. Ching, Becoming Japanese, 180-185, and Faye Yuan Kleeman, Under an Imperial Sun: Japanese Colonial Literature of Taiwan and the South, (University of Hawai'i Press: 2001), 79-81. For more on Song in particular, see June Yip, Envisioning Taiwan: Fiction, Cinema, and the Nation in the Cultural Imaginary, (Duke University Press: Durham, 2004), 45-46 ${ }^{36} \mathrm{Wu}$ Zhuoliu, The Fig Tree: Memoirs of a Taiwanese Patriot, trans. Duncan Hunter (Authorhouse: 2002), 154
} 
That Wu completed the novel prior to the formal surrender of Japan in August 1945 gives a palpable sense of urgency and apprehension to the story's tone, atmosphere, and content. Had it been published while the Japanese were still in power, the work would have been treated as subversive by authorities, who began to clamp down on Taiwanese publications and insurgent behavior as the Pacific War progressed. In the preface to the 1956 edition of Orphan (published in Japanese), Wu wrote, "If (the manuscript) were to be discovered, I would be immediately put away as a traitor or antiwar supporter." 37

\section{Synopsis}

Orphan of Asia follows the life of Hu Taiming, a Taiwanese man born near the beginning of Japan's colonial administration of Taiwan, and spans nearly the entire Japanese colonial period, from $1895^{-1945}$. The young Taiming is initially raised on Chinese tradition by his grandfather Old $\mathrm{Hu}$, and is sent to a private classical Chinese school, but is soon forced to enroll in the Japanese educational system. Taiming eventually finds himself estranged from both Chinese and Japanese cultures: he tries working in Japanese schools, and studying for a degree in a prestigious Japanese university. However, he is never fully accepted in Japan, and also feels distanced from his own home culture when he returns to Taiwan. Taiming wanders to China, where he teaches successfully for years and marries, but is eventually imprisoned by Kuomintang police and accused of spying for the Japanese around the beginning of the second SinoJapanese War. Taiming manages to escape back to Taiwan, yet he is separated from his new family in Nanjing. He is drafted against his will into a support unit for the Japanese army in Guangdong, and is looked upon as a foreign invader by local Chinese. Taiming

\footnotetext{
37 Wu Zhuoliu (Go Daku-ryu), Aijia no koji [The Orphan of Asia] (Tokyo: Shinjinbutso, oraisha, 1956)
} 
is discharged and sent back to Taiwan after suffering a nervous breakdown, where he lives in under an increasingly oppressive and hypocritical colonial government. After witnessing one final injustice (his brother is worked to death in a forced labor unit), Taiming loses his mind, paints vehement denouncements of the imperial "bandits" on his household walls, and eventually disappears altogether.

Orphan of Asia is a short book, but it channels many philosophical meditations through its disaffected protagonist. Here I lay out the major themes of the novel, assimilation and abandonment, and state the importance of Wu's book in considering the problem of Taiwanese identity.

The first theme I analyze is the symbolic and political abandonment of Taiwan by the Chinese in Orphan. The novel situates Japanese-ruled Taiwan in an impossible political and cultural bind, rendering it the "orphan" of both China and Japan. In China Taiming often encounters Chinese who refuse to see him as anything other than an untrustworthy Japanese national. The irony is that Taiming was raised on Chinese classics, and recalls fables or quotes scholars of classical tradition whenever he seeks refuge from real-world problems. Ultimately, his beloved classics cannot prevent his mind from being destroyed by colonial injustice and contradiction, although he becomes something of a martyr for the villagers who are full of silent resentment for the imperial authorities.

Taiming's "abandonment" is particularly traumatizing because he had been raised to view Chinese as kin, as sharing a common cultural descent. The complexity of identity in Orphan is suggested by the narrator, who frequently refers to the "Taiwanese 
people," as opposed to Chinese "of Taiwan" or "Japanese." This distinction is made clear when Taiming attends a lecture sponsored by the Academic Association of China in Tokyo. Taiming greets the other young attendees in the "Chinese spoken in Taiwan" (the Min-nan o Hokkien dialect, which is also spoken in Fukkien and other parts of southern China), who mistake him for a southern Chinese. Taiming remains silent about Taiwan. He also does not know who is giving the speech, he only knows that it is "a very important person from China." This speaker rapidly communicated ideas on nation building and Sun Yat-sen's "Three Principles" (Ethnic unity, democracy, welfare), yet Taiming "did not feel moved in the least" because of his weak Mandarin. In hindsight this is deeply ironic, considering the fact that Sun Yat-sen's Three Principles of the People were to be the foundation for the Chinese Nationalist Party's administration of Taiwan after $1945 \cdot{ }^{38}$ After the event, Taiming finally admits to a Cantonese student that he is from Taiwan, a confession that sparks immediate disgust. The information spreads amongst the young people, who become hushed and begin to murmur, "He might be a spy." Soldiers recruited in Taiwan, the narrator reveals, have been involved in some of Imperial Japan's provocations in China. 39

Wu's elaborates on the distinction between Taiwanese and Chinese through his characterization of the Mainland politicians and bureaucrats in his memoir, The Fig Tree. Wu wrote, "There were people of integrity" amongst those who had come over from Chungking to reclaim Taiwan, but they had an "inflated sense of their own importance and their only concern was to feather their own nest."40 Wu describes an incident in a neighborhood council meeting in which a mainland official reproached

38 "The Three Principles of the People" is also the first line of the Republic of China's National Anthem. 39 P.80 ${ }^{40} \mathrm{Wu}$, The Fig Tree, 216 
locals upon hearing them speak Taiwanese. Wu was cautious but critical of the mainlanders' "unprincipled behavior," and in an April 1947 article titled "How can Taiwan become a better place?" he expressed the view that "For the last three hundred years Taiwanese have never known a government they could trust [...] For Manchus and Japanese alike. Taiwan was a colony where principled behavior had no place." ${ }^{41} \mathrm{Wu}$ concludes that Taiwanese had become a suspicious people. The rest of the article reads as a veiled moral warning to the Kuomintang to abide by Sun Yat-Sen's democratic principles.

If Wu recognized the Kuomintang as a foreign political entity that garrisoned troops, censored publications, and suppressed local linguistic practices, why does he seem to adhere to the standard rhetoric that the Kuomintang "reclaimed Taiwan" unironically? Partly because many Taiwanese genuinely desired just government which adhered to Sun Yat-sen's Three Democratic Principles. Perhaps what the Chinese Nationalists "reclaimed" with regards to Taiwan was the people's trust in the ideals of democracy and the hope for political autonomy, not ethno-nationalism or the trappings of "Chineseness." Wu wrote in a later entry, however, that despite Kuomintang propaganda about the Three Principles of the People "as a way to government by the people," Taiwan was still subject to government "by a clique of outsiders."42 Wu also recounted a moving experience in late 1946 after he resigned from his work at a newspaper when its new director discontinued all Japanese content. Wu's friends removed his old home's window panes because they told him that the windows "would be gone within an hour" of his departure. Crime from migrant Chinese and a general

${ }^{41}$ Ibid., 221

42 Ibid., 233 
lack of order was a widely criticized feature of the Kuomintang arrival, but worse was yet to come.

On the morning of February 27, 1947, Wu was working at a different newspaper when the tensions between Taiwanese and Kuomintang reached a tipping point. A colleague rushed to him with the following story: six inspectors from the Public Monopoly Bureau became involved in an altercation with a Taiwanese woman selling contraband cigarettes, and threatened to take her stock and earnings. As the woman pleaded to the officers, one struck her with a revolver. As she crumpled to ground, her young daughter nearby screaming, bystanders closed in on the officers. Before fleeing, the officers fired a warning shot that happened to kill a bystander watching events from his doorway. A massive wave of protest ensued in Taipei, which soon engulfed the rest of Taiwan as news spread over the course of the day. On the 28th, as protesters marched toward the residence of Administrator General Chen Yi (who was massively unpopular; Wu claims many locals saw him as a businessman milking Taiwan for his own profit), machine guns began strafing the crowd. In a "paroxysm of rage," the Taiwanese in the crowd set upon the mainlanders, breaking into government buildings, including the Monopoly Bureau, ransacking and beating their occupants.

Interestingly, Wu noted, "only the official portrait of the Nation's Father remained untouched by their mad rampage -- a silent testimony to the reverence and patriotism he inspired." 43 As temporary martial law was declared (that, starting again in early March, was to last thirty-eight years), government troops clamped down on the rioters. Wu totaled the casualties of government workers at thirty-three dead and over

43 Ibid., 240 
eight hundred injured. The local Taiwanese suffered losses much greater. Eventually, Chen Yi was recalled and replaced by General Bai Chongxi, a man many perceived to be more competent. Although the February 28th Incident was an "indelible stain" on Taiwan's history, life nonetheless "rapidly returned to normal."44 Wu finishes his memoir by including some work written during the transition years in Taiwan Before Dawn: "Creating a Taiwan of material and spiritual wealth, a Taiwan of freedom, is the task of everyone living here, and in this respect I make no distinction between mainlanders and Taiwanese."45 Although Wu characterized this goal, which had not changed over twenty years between 1947 and 1967 when he penned his biography, as difficult as "moving mountains," he nevertheless remained optimistic that Taiwan could achieve greatness under Kuomintang rule.

This optimism seems to waver, however, in the final chapter of his autobiography. Wu compared the Japanese era to the new Kuomintang administration in, that "just as today, we Taiwanese could not then rid ourselves of our colonial subject mentality; we had no sense of being sovereign or independent." Wu critiqued the lack of (political) idealism among Taiwanese youth, who instead complained without acting and let "baser sentiments" take over. He observed that Taiwan's intelligentsia had thought that "Restoration" (to the mainland government) would mean freedom and a better life, but in reality what it brought was "indistinguishable from what they had known under colonialism." 46

\footnotetext{
44 Ibid., 254

45 Ibid., 263

46 Ibid., 234
} 
We can identify several points from this foray into the early Kuomintang years that aids in our analysis of failed assimilation in Orphan of Asia. Unlike many commentators after martial law was lifted, especially politicians and writers aligned with the Democratic Progressive Party (which the current president of Taiwan, Tsai Ying-wen, represents), $\mathrm{Wu}$ does not characterize the difference between the mainlander Kuomintang and Taiwanese as inherently cultural. Instead, the sources of tension were governmental corruption and "unprincipled" behavior. Likewise, in Orphan, Taiming does not generally perceive all Japanese or all Chinese as wicked, but instead views quarrels between individuals and nations as the product of poisonous political trends that hold rationality hostage. Taiming's liberal-minded Japanese friend Sato attributes Japanese "high politics" with dividing the Taiwanese from the Chinese, and the Taiwanese from amongst themselves, as with the Musha Incident of 1930.47 Despite this, there are positive Japanese influences, like Sato himself, who encourage the development of Taiwanese cultural and political movements despite the unsupportive colonial government. In 1945, just as in 1967, Wu (through Taiming) did not characterize ethnic discrimination as the root of colonial Taiwan's problems, but instead criticized the manipulative systems and hypocritical ideologies that gave power to ethno-nationalist distinctions, and that in turn allowed the colonial government(s) to exploit subjects while claiming to do so for public benefit.

\section{$* * *$}

The second theme I address is disillusionment. Wu juxtaposes two worlds in the novel: that of the classical China, and that of the emerging colonial modernity

\footnotetext{
47 A violent Aboriginal revolt in central Taiwan. I discuss the Musha Incident in more detail in Chapter Four, as Seediq Bale (2011) is based on it.
} 
represented by Japan. Although the young Taiming is curious and enthralled by both worlds, he eventually becomes disillusioned with what he sees after living in both Japan and China. The China he steps into is itself semi-colonized, semi-westernized and warridden; a veritable "sick man of Asia." 48 Though the material world of modern Japan and the educated and civil populace initially attract him, he realizes through his interactions with the Japanese that he cannot possibly penetrate the ethno-national boundaries separating him from them.

Chinese culture and tradition is a crucial element of Taiming's identity. Most of this classical tradition is presented in the form of anecdotes from his grandfather and lessons from Taiming's own readings. Whenever Taiming feels uncertain or apprehensive about something, he finds refuge in quoting ancient scholars and poets. Indeed, the only place Taiming feels at home is when he is engrossed in studies, or thinking about scholars of antiquity, whom he often believes have relevant solutions to present-day troubles. However, even Chinese antiquity presents problems for Taiming because it conflicts with other "modern" beliefs that were inculcated during his years in Japanese secondary education. For example, he refuses to take a concubine, and attributes much family strife to his father's decision to take a second wife. He perceives himself as modern in this regard, and yet he is castigated by his wife for having "oldfashioned ideas" about how women should behave when he criticizes her for drinking and gambling with colleagues. Taiming is in all respects a cultural and political "orphan" of China and Japan, both of which reject him.

${ }^{48}$ Leo T.S. Ching, Becoming Japanese, 201 
Another source of disillusionment for Taiming is "politics." For someone with a penchant for the literary and scientific, Taiming spends a lot of time around friends who are politically active, and who continuously urge him to participate in some kind of political activism. In Tokyo, for example, Taiming's friend Lan continuously tries to persuade Taiming to write for a political magazine marketed at young Taiwanese. 49 Although Taiming rejects this offer, years later he becomes involved briefly in a political magazine in Taiwan under Sato, a liberal-minded Japanese newsman, whose goal was to “make a positive difference (by elevating Taiwan's literary standards) without falling afoul of the government's extreme censorship rules."50 Taiming's job collecting testimonies from Taiwanese intelligentsia felt "worthwhile," but once Sato leaves after American air raids begin, the gazette is shut down. Sato leaves Taiming with the following parting words: “Theory without practice is just empty [...] [you're] too much of a poet, too pure [and] not good at dealing with reality." ${ }_{51}$

Indeed, Taiming is perennially let down by the divisive politics of his situation: he is arrested in Nanjing because authorities suspect he is a spy, and he is later forced to serve as a support unit in Japanese forces occupying Guangdong, where he feels the locals' eyes full of "silent resentment" trained on him. After witnessing an execution Taiming suffers a mental breakdown and returns to Taiwan. Ultimately, Taiming is driven to insanity after watching his half-brother die before him from exhaustion after having been coerced into joining the "volunteer" work squadron. It is ironic that once Taiming disappears, a rumor circulates that Taiming had gone to Kunming, China, to work as an anti-Japanese radio broadcaster. This seems unlikely, as it was partially

$49 \mathrm{Wu}$ Zhuoliu, Orphan of Asia: a Novel, trans. Ioannis Mentzas, (Duke University Press: 2004), 59 50 Ibid., 223

${ }^{51}$ Ibid., 233 
"politics" that drew him over the edge. Specifically, it was the kind of manipulative colonial politics (kominka, which I discuss in detail below) that prevented him from being able to identify as "Chinese," "Japanese," or "Taiwanese," and which thus forced him to migrate endlessly between these territories.

Taiming's madness is thus a culmination of decades of spiritual vagrancy, and of a lifetime of disillusionment. It is only triggered by his brother's death, a final blow that renders his home village, the last safe haven, a place of immeasurable sorrow. The remnants of Taiming's shattered and pitiful psyche are transcribed into words on his family home's wall, which remains for the locals to revisit as a form of silent protest.

The final theme I discuss revolves around “colonial subjectivity," specifically the failure, or "incompleteness," of Japanization. Orphan of Asia deals with the fallout of Japanese imperialism in a predominantly Han-Chinese cultural environment. Although Taiming and many characters in the story struggle at one point or another to "become" Japanese by adopting Japanese customs and names, and by embracing Japanese learning, they are nonetheless thwarted by their racial and cultural heritage. Wu depicts Japanese authorities in Taiwan as refusing to treat locals on equal terms, even when locals were willing to assimilate, and exploiting the people as if they were work animals. I now touch on the shifting character of Japanese colonial policy to provide context for my analysis. To fully understand Wu's characterization of Taiwanese subjects as caught in a double-bind, we need to understand the paradoxical nature of Japanese colonial policies in Taiwan. 
Historian Mark Driscoll argues that Japanese imperial governments in East Asia progressed from a "biopolitical" administrative style (like in Taiwan) to an aggressive "necropolitics," (Korea and Manchuria) in which labor populations became so exploited that they were no longer being regulated with the aim of sustaining or reproducing themselves. $5^{2}$ Though Taiwan fared considerably better than Korea and Manchuria in the 1930s-1945, it nonetheless suffered under an increasingly nationalistic and fascistic imperial regime, one which became less tolerant of divergent "identities" or "nationalisms" among its subjects.

In short, Driscoll claims that methods of administration on the colonial periphery in places like Taiwan, were "experiments" that aided the formation of an ominously efficient total war political-economic system that culminated in the disastrous wartime treatment of Korean and Manchukuoan subjects. Under governor general Goto Shinpei, Taiwan seems to have been administered through "biopolitics," a Foucauldian concept. In a lecture from Society Must be Defended, Foucault postulated that gradually over the 19th century, states enjoyed a new right to administer the process of "making live and letting die," which replaced the old sovereign's "taking life and letting live."53 According to Foucault, techniques of power emerged over the course of centuries, which centered on the control and organization of biological bodies. States ruled over populations as biological masses whose size and productive capability were influenced by such parameters as mortality, fertility, and longevity. The emerging state, in the field of

$5^{2}$ Driscoll, Mark, Absolute Erotic, Absolute Grotesque: The Living, Dead, and Undead in Japan's Imperialism, 1895-1945 (Duke University Press: 2010).

53 Michel Foucault, "Society Must Be Defended, Lectures at the College De France, 1975-76" ed. Marlo Bertani and Alessandro Fontana, trans. David Macey (Picador: New York, 2003), 247 
biopolitics, thus treated populations as "political problems," problems that could be solved through the exercise of the "power of regularization" 54 States thus initiated projects to "rationalize" humanity's relationship to geographical environments, diseases, and even spontaneous day-to-day accidents through insurance, education, safety measures, and public works.

Japan's seizure of Taiwan in 1895 represented the beginning of an experiment, the beginning of a crash course in biopolitics. Statesman Yosaburo Takekoshi's 1907 account, Japanese Rule in Formosa, is a useful source of reference in this area. 55 This text is a survey of Japan's "successes" in the modernization of Taiwan up to 1907, with in-depth evaluations of the island's economy and production, the condition of state monopolies (opium, salt, and camphor), land distribution, police administration, public health, communications, and education. Takekoshi commented on the relationship with metropole Japan, and also provided detailed historical, geographical, and ethnological accounts of the inhabitants of Taiwan, including a section on the "Savages and their territory." 56 Japanese Rule in Formosa is essentially a "ruler's manual" of the island, a biopolitical textbook. It is also a powerful statement to Western imperialist nations, who had been reluctant to accept Japan as an equal on the world stage. Takekoshi wrote in "A Word to My Readers,"

Western nations have long believed that on their shoulders alone rested the responsibility of colonizing the yet unopened portions of the globe, and extending to the inhabitants the benefits of civilization; but now we Japanese, rising from

54 Ibid., 246

55 See the account by American diplomat James Wheeler Davidson, The island of Formosa, Past and Present (London and New York: Macmillan \& co.; Yokohama [etc.] Kelly \& Walsh, ld, 1903) for another source that shows the methodologies and outcomes of early Japanese rule in Taiwan.

${ }_{5}^{6}$ Yosaburo Takekoshi, Japanese Rule in Formosa, with a preface by Baron Shimpei Goto, trans. George Braithwaite (Longmans, Green, and Co.: 1907), x 
the ocean in the extreme Orient, wish as a nation to take part in this great and glorious work. Some people, however, are inclined to question whether we possess the ability requisite for such a task. I felt that these would doubt no longer, could they but read the account of our successes in Formosa. 57

Takekoshi's account provides both an "official history" of the island's then recent affairs, and a projection for future development in Taiwan. $5^{8}$ The quote above also provides insight into what Japan hoped to achieve through effective colonial governance of Taiwan: parity with the Western world. This was not to be granted, for Western powers unanimously rejected Japan's "Racial Equality Proposal” treaty amendment in the 1919 Paris Peace Conference. This rejection, along with the termination of the 1902 Anglo-Japanese Alliance in 1923, served to distance Japan from Western powers in such a way that influenced its increasingly nationalistic stance (and alignment with Germany) prior to World War Two.59

Yosaburo Takekoshi in 1907 could not have foreseen the drastic change in Imperial politics as Japan became involved in conflict with China and began expansion into other Asian territories in the 1930s. The "necropolitics" Driscoll describes in relation to Korea and Manchukuo revolved around the complete commoditization of human life and labor under the "total war" economy in the 1930s and 1940s. Although Driscoll does not touch on wartime Taiwan in detail, virtually every source that deals

57 Ibid., vii

${ }^{58}$ Goto Shinpei, chief of civil administration in Taiwan from 1898 to 1905 , supported this text and wrote a preface for it. Of course, Takekoshi was well aware of (but did not mention) the fact that Japanese authorities encountered severe resistance from Taiwanese (of all walks of life) in the first decade of occupation, and retaliated with such disproportionate force that politicians in Tokyo protested, and the Imperial family donated funds for reconstruction of destroyed villages. For more on Taiwanese resistance in the early years of Japanese occupation, see Denny Roy, Taiwan, A Political History (Cornell University Press: Ithaca and London, 2003), 36.

59 See Malcom Kennedy, The Estrangement of Great Britain and Japan, 1917-35. (Los Angeles: University of California Press, 1969), 56-57 
with Taiwan's wartime history indicates a similar (albeit not as complete) shift in colonial government, toward nationalistic policies aiming to convert the people of Taiwan culturally to boost the war effort.

Early Japanese colonial policy in Taiwan centered around "Doka," (assimilation, 同化) which spanned from around 1915 to 1937, and "Kominka" (imperialization, 皇民 化), which spanned from the formal beginning of the Second Sino-Japanese War in 1937 to the end up Japanese rule in Taiwan. In general, the early colonial period centered around the establishment of order and economic development on the island. Between 1895 and 1905, the Japanese government increased Taiwan's railroad mileage from thirty to three hundred miles, with several thousands more planned or under construction. In 1903, the Japanese constructed hydroelectric generators near Taipei, which meant that Taiwan would become the first Asian country to use electricity besides Japan. Electricity in turn aided the development of small industries, and as a result Taiwan was able to transition to a cash economy. By the start of the Doka period, the Japanese had closed out foreign enterprise in Taiwan, leading to the eventual development of heavy industry in the 1920 s and 30 s and increased exports. The Japanese also improved Taiwan's public health and hygiene dramatically; bubonic plague was eradicated, and instances of cholera, smallpox, dysentery and malaria were significantly reduced. Taiwan's literacy rate also skyrocketed during the Japanese era, as did technological skill. Old Chinese customs, such as female foot-binding, were outlawed. ${ }^{60}$

\footnotetext{
6o James F. Copper, Taiwan, Nation-State or Province?, 6th ed., (Westview Press: 2013), 40
} 
Despite the obvious beneficial side of Japanese colonial rule, historian James Copper points out that there was also a "discriminatory and predatory element" to Japanese policies. Social policies, despite boosting technical expertise and literacy rates, were largely carried out with little understanding of or concern for local Taiwanese culture and sentiment. Taiwanese were forced to learn Japanese, and while they were encouraged to study medicine, engineering and other science related subjects, there were very few avenues available for Taiwanese to advance into legal or political careers. Few Japanese migrated to Taiwan for reasons other than for governmental posts or business, and the Japanese who did reside there sent their children to all-Japanese schools and lived in segregated residential areas. Both Ching and Copper concur that Japanese attempts at assimilation were "half-hearted," in the sense that feelings of ethnic superiority and cultural "exclusivity" impeded efforts to fully incorporate Taiwanese into Japanese cultural systems. ${ }^{61}$ The contradictory reality of Doka, argues Ching, was that while Taiwanese were encouraged to "become Japanese on the level of formal approximation," through language, dress, mannerism, and the performance of rituals, they were also denied substantial political representation, and economic equality. 62

Ching also suggests that the implementation of the Kominka movement was not a mere extension of Doka. Kominka exuded a sense of urgency, a need for a massmobilization of Japan's colonial subjects behind the imperial war effort. Now, Taiwanese were not simply urged to "become" Japanese, but to become good Japanese. Taiwanese increasingly adopted Japanese surnames, and public exclamations of "Long

\footnotetext{
${ }^{61}$ Ibid., p.41

${ }^{62}$ Ching, Becoming "Japanese," 104
} 
live the Emperor!" became commonplace rituals. Crucially, Kominka coincided with increased mass-mobilization as Japan entered the Second Sino-Japanese War and World War Two. The colonized were encouraged to "act, live and die for the emperor." Few people in Taiwan protested against "Japanization" and Kominka during the war years, with the notable exception of the 1930 Musha incident, which I discuss in Chapter Four. Additionally, over 207,000 Taiwanese men (even including those from central Taiwan's aborigine populations that had long been a thorn in the colonial government's side) volunteered to serve in Japanese military forces between 1937 and $1945 .{ }^{63} 64$

However, the absence of violent resistance did not mean that Taiwanese could, or desired to, fully assimilate in cultural terms. During the 1920 s and 30 , Taiwanese elite who sought the establishment of a Taiwanese parliament submitted no less than fifteen petitions to the Imperial Diet. This movement gained widespread support amongst Taiwanese landowners, merchants, and intellectuals, as well as liberal-minded Japanese politicians and educators. Though the movement did not demand legal or economic autonomy, it was still labelled a "Taiwanese nationalist movement," because it made reference to a unique "Taiwanese" cultural system. Although every petition submitted ended with "pledges of allegiance and loyalty to imperial Japan," the Japanese government, concerned that the movement would lead to the secession of Taiwan from the Empire if unchecked, sought to minimize its influence by rejecting all its petitions. ${ }^{65}$

\footnotetext{
${ }_{3}$ Ching, Becoming "Japanese," 94

${ }^{64}$ Christopher Hughes, Taiwan and Chinese Nationalism, National Identity and Status in International Society, (Routledge: 1997), 22

65 Ching, Becoming "Japanese," 57-58
} 
Historian Hsu Chien-Jen points out that such publications as the Taiwan People's News advocated retaining written Chinese in Taiwanese school curriculums on the grounds that it represented the "spirit of Han people in Taiwan."66 Tsai Pei-huo, publisher of The Formosa Youth, was an opponent of Japan's Doka policy in Taiwan and in 1920 wrote that "harsh" attempts at Japanization that suppressed local cultures were being conducted in vain. Another newspaperman, Tsai Shih-ku, published an article in 1921 that suggested, "Taiwan possessed a unique culture and history which were distinct from the Japanese."67 Hsu takes this as suggestive of an emergent "Taiwan consciousness," 68 an idea concurrent with Ching's in-depth analysis of Taiwanese "komin literature," that a kind of "Taiwanese identity" was shaped precisely because of an earnest, but ultimately unsuccessful, attempt to "become Japanese" on the part of many Taiwanese. In other words, the Taiwanese Han had been faced with their "nonChineseness" in their willingness to accept and adapt to life under Japanese government, but also realized their "non-Japaneseness" in an inability to fully abandon aspects of Han culture.

A good example of Wu's treatment of the failure of assimilation under lateImperial policy in Orphan is the contrast between the first depiction of "New Year's day," when Taiming is a young boy, and the later depiction of the same celebration during the war years. When Taiming is around ten years old (approximately 1910), he and his

\footnotetext{
${ }^{66}$ Hsu Chien-Jung, The Construction of National Identity in Taiwan's Media, 1896-2012, (Brill: 2014), 29 ${ }^{67}$ Ibid., p.28

68 Tai-wan yi-shih (台灣意識), literally Taiwan(ese) consciousness, is a common yet ambiguous term used in debates about Taiwanese identity and nationalism. Some conflate the term with "Taiwanese nationalism" but this interpretation is inadequate and problematic. If we are to understand this term, as Hsu uses it, to mean Taiwanese consciousness of self, then in this context it logically refers to Taiwanese identifying their selves and social condition as defined in contrast to $p$, with $p$ being that of the Japanese imperialists.
} 
grandfather participate in New Year celebrations in accordance with the lunar ("farmer's") calendar.69 Taiming's family sacrifices a pig to worship the "Son of Heaven," and he and Old Hu wear formal Chinese gowns and perform "Three offering bows" to the deities Guan Yin, Guan Di, and Ma Tzu, to give thanks for the preceding year and pray for the Hu family's continued prosperity and fortune. Red couplets are pasted on household doors, firecrackers are lit everywhere, and people relax for around fifteen days by eating, drinking, gambling, and visiting ancestral tombs. The celebration, "though nothing new," facilitated an auspicious mood and "congratulatory spirit" for the New Year. ${ }^{70}$

This depiction contrasts starkly with a different kind of "New Year" during the Kominka war years. The narrator announces ominously, “A year during war is equivalent to a hundred years in peacetime. With violent tempo and pressure unseen in peacetime, everything is about to be changed. The customs and habits rooted in the history and tradition of the Taiwanese people are no exceptions." Under increased Japanese influence, Taiming's village (like the rest of the island) replaced the lunar with the solar calendar. The festival that once enthused "tens of thousands of people" now seemed like "the fire had burnt out of it." It was a celebration of "mere formalities, devoid of emotion." Taiming's dissatisfied mother, however, "furtively" prepared sweet cakes "with lingering attachment" and worshiped ancestors and Ma Tzu when the lunar New Year came around again. 71

\footnotetext{
69 New Year celebrations according to the lunar calendar are still observed in Taiwan today. 70 Wu Zhuoliu, Orphan of Asia, 10 ${ }^{71}$ Ibid., p.186
} 
Leo Ching points out in his comparison of the two New Years that "unlike earlier periods of colonial rule, where the precarious relationships among cultural variables were allowed to coexist, colonialism during the war became both dominant and coercive in its insistence on singularity (of) identity." 72 Wu implies in Orphan that this effort could not succeed in genuinely winning over or "converting" the people of Taiwan, though it did create opportunistic "sycophants" like Taiming's brother Zhigang, who adopted trappings of Japanese culture in order to seek their own enrichment under the colonial regime. Had the war not interrupted Japanese colonial rule in the way it did, cultural life of Taiwan might have travelled along a drastically different path. However, Taiming's haunting chant at the end of the work confirms the exploitative character of Japan's administration of Taiwan in the 1940s:

The head of the family is the big brother

The big brother is the head of the thieves

People are skinned

Trees are skinned

Mountains are skinned73

This utterance evokes strong feelings in village onlookers, who recall that the country's mountains, trees, plants, food had all been harvested by the colonial government. People, though not skinned, were "whipped like horses" and worked to death. This was a

${ }^{72}$ Ching, Becoming "Japanese," 208

73 Wu Zhuoliu, Orphan of Asia, 245 
far-cry from the official messages of progress and unity that the government trumpeted.74

Ultimately, Taiming never reconciles his cultural identity with his surroundings, even when enjoying the superficial comforts of family and home. His entire life is pervaded with helplessness: he cannot be "neutral" in war between China and Japan despite his personal aversion to violence due to the colonial status of Taiwan. He also cannot truly "assimilate" into Japanese or Chinese culture because of linguistic, cultural, and ideological barriers. Because of his "orphan" status, Taiming becomes a stranger in his own country. The only constant he finds there is the desperate, silent anger and powerlessness of his oppressed countrymen. Taiming's madness and disappearance is therefore the product of failed biopolitical management: the state does not ensure his continued "life," but neither is he intentionally left to die. He is simply forgotten.

Orphan of Asia represents one of the most stirring protests against the failure of the imperial assimilation project, and though one could argue that Taiming suffers from a nascent, and unacknowledged, form of "Taiwanese consciousness," I do not believe that "Taiwanese consciousness" in this context represents a type of "nationalism." I believe that some Taiwanese scholars tend to stretch an interpretation of Orphan of Asia in order to fit the text into a deeply political analysis that relies heavily on contemporary political motivations, or at least an (in this case, 1980s) habitus that favored the International Relations category of (nation-)state as a desirable and necessary designation for actors on the world stage. The attempt to "prove" or outline the historical formation of a Taiwanese nation through two colonial eras in the twentieth

74 Ibid., 247 
century, by combining literary and historical approaches, is certainly an interesting project.75 However, if we return to the text, can we really say that there is a "Taiwan consciousness" as opposed to a "Japanese consciousness" (or even more ambiguously, “Chinese consciousness”)? I don’t think Wu could have employed this framework when he wrote Orphan. I find it more plausible that the Hu family's fate and Taiming's insanity represent a rejection of the "political order" that $\mathrm{Wu}$ (and Taiming) lived through, in which colonized peoples on Taiwan like Taiming could not participate in the "game of nations" because their marginal and subjected status on the world stage denied them a claim to their own unique culture. Instead, people like Taiming suffered in a Sisyphean struggle to conform to categories that could never admit them: they were nominally subjects of japan, but could never become fully Japanese. Culturally, they derived much from Chinese tradition, and yet they were disowned as traitors and Japanese collaborators by Chinese (both on the mainland, and later by Kuomintang sympathizers who arrived in Taiwan) in the 1930 s and 40 s

Although it is a stretch to claim that the Japanese colonial era fostered a kind of "Taiwanese nationalism," it certainly does seem to have facilitated a new Taiwancentered perspective in the works of local thinkers and writers like Wu. Before 1895, Taiwan was a backwater of the Qing Empire, of little political or economic importance to China proper; it was even less noteworthy culturally. Taiwan was not even fully colonized or administered by the Qing. But after fifty years of Japanese rule, and the

75 Such historians and literary scholars as Hsu Chien-jen, Chen Fangming, and Yin Zhangyi, who are advocates of "Taiwan consciousness." For more, see Tang Xiaobing, "On the Concept of Taiwan Literature," in Writing Taiwan: A New Literary History, ed. David Der-wei Wang and Carlos Rojas (Duke University Press: 2007), 62-65 
technological modernization and political centralization that came with it, Taiwan's population was left much healthier and more economically productive than had been the case previously. Wu's reference in his memoir to the Kuomintang as a "clique of outsiders" assumes a Taiwan-centered perspective that would have been implausible before 1895, when Han settlers would have been inhabiting a space that was more an outpost than a functioning state. Had it been the case that Taiwanese intellectuals in Wu's generation fully perceived themselves as a lost generation of Chinese, who had merely been waiting half a century for China to "reclaim" them, they would hardly have characterized the Chinese Nationalists as an external group. But it is also inaccurate to claim that Wu's perspective indicates a separate Taiwanese nationalistic sentiment; even less does it indicate that Wu considered Taiwan a separate nation. Instead, Wu contents himself with highlighting points of resemblance and difference between the Taiwanese on the one hand, and Chinese nationalists on the other. The differences between the two groups were not as extreme as those between the Taiwanese and the Japanese, but they were nonetheless sufficient to create a similar colonizer-colonized relation, implying an imbalance in power and social hierarchy. After all, there is a reason why Wu's novel was built around the image of an orphan.

Ultimately we can interpret Orphan of Asia as a cautionary tale, and as a protest against two colonial governments. Wu suggested that a life in shackles, of incessant politicking and brooding, necessarily destroyed sensitive and sentimental men like $\mathrm{Hu}$ Taiming. The fact that Wu published this novel - in 1946, in Japanese - can also be read as a political warning to the Kuomintang administration against the path of corruption and hypocrisy, which Wu clearly opposed on multiple levels. Most important, Wu's 
novel sold well, and Taiming's status as an Orphan of Asia resonated with a readership that was already disillusioned by the new government. Although the obvious alien oppressors had been vanquished in 1945, Taiwan seemed merely to have switched hands to another set of adoptive parents who sought to enrich themselves at the expense of local Taiwanese. The sense of disillusionment with the Japanese that Wu articulated in Orphan and in his memoir carried on into the Kuomintang years in general. Nativeborn Taiwanese of the Kuomintang years tended to see themselves as semi-colonials, which may have been worse because of the cultural affinity between them and the outsiders who now ran the affairs of the island.

In the following chapter I explore the depiction of this semi-colonial Taiwanese life developed in the 1989 blockbuster film A City of Sadness, a direct critique of the Kuomintang. In light of other native film and literary movements in the 1970s-80s, I believe that the legacies of City and Orphan represent the foundations of a "postnationalist" Taiwanese identity. 


\title{
Chapter Three
}

\section{Political Art, Impressionist History: Hou Hsiao-hsien's A City of \\ Sadness and Taiwan's Nativist Literature Discourse}

\begin{abstract}
Seventeen years have passed since Restoration/ And the sores have still not healed/ An evil gentry cheats the commonfolk/ Tax collectors blackmail the businessman/Corrupt officials spend their days in restaurants/ "Freedom!" they preach, but do not practice/ And few men sorrow for what the country has become/ fifty long years we passed as slaves/ Fifty years we cannot now reclaim/ But pain passes, the suffering is forgotten/ The country's plight is what concerns us now The shameful days of history must be left behind/ While bent officials scheme with racketeers/ The city, dejected, suffers endlessly/ We hated what Shimonoseki wrought/ Yet what, we ask, has Restoration brought?
\end{abstract}

-Wu Zhuoliu, Thoughts on Restoration Day (1951) 76

The Japanese imported cinematic technologies to Taiwan in 1901, but the few productions that emerged in the early twentieth century were under heavy, if not complete, Japanese influence. Despite this, cinema was a popular form of entertainment and films were even shown in remote villages through the use of a generator, a white cloth, and a benshi, a narrator who commented on action during the film. After the Kuomintang took over Taiwan, Taiwanese cinema was characterized by the party's desire to impose Mandarin Chinese across the island, to "Sinify" it. The Nationalists, and many mainlanders who arrived in Taiwan, looked down on the local culture as a

${ }_{76}$ Under the terms of the Shimonoseki treaty of April 17th, 1895, Qing China relinquished Taiwan to Japan. Excerpted from Wu, The Fig Tree, 186 
mixture of Chinese outback and Japanese imperialism. 77 By 1955, the Kuomintang created several well-funded film studios, most notably the Central Motion Picture Corporation, and smaller-scale Taiwanese productions all but disappeared. Early CMPC productions were largely propagandistic, but the quality of films gradually improved through collaboration with experienced Hong Kong producers. However, after the 1970s, Taiwanese film would move significantly beyond the escapist kung-fu, historicalromance genre which had become standard fare for local viewers. 78

In 1971, the PRC forced Taiwan out of the United Nations, and by 1979, the United States broke off formal relations with Taiwan in order to normalize relations with the PRC.79 In the midst of this diplomatic isolation, the Kuomintang sought to "revitalize" Taiwanese film with the hopes that it could become a powerful diplomatic tool. "New Taiwanese Cinema" was thus born, largely due to efforts of Kuomintangbacked studios like the CMPC. In 1980, the CMPC hired Wu Nien-jen and Hsiao-yeh, both established Taiwanese writers, who cooperated with director Edward Yang to make a series of short films. Eventually, the writers contacted Hou Hsiao-hsien, a recent art school graduate born in China but raised in Taiwan, who was trained in both directing and screenwriting. Hou's early films, such as Green, Green Grass of Home (1982) showed the director's penchant for grounded, realistic stories that were inspired by the lived experience of his siblings who were rural schoolteachers. ${ }^{80} \mathrm{Wu}$ Nien-jen and Hou Hsiao-hsiens' early collaboration as screenwriters resulted in Growing Up (1983) a

\footnotetext{
77 Thomas B. Gold, "Civil Society and Taiwan's Quest for Identity," in Cultural Change in Post-war Taiwan, ed. Steven Harrell and Junjie Huang (Boulder, Co.: Westview Press, 1994), 60

${ }^{78}$ Bérénice Reynaud, Hou Hsiao-hsien's A City of Sadness, BFI Film Classics (British Film Institute: 2002), 20

79 Yvonne Chang holds that it was primarily diplomatic setbacks such as this that triggered the Taiwanese Nativist literary movement. See Yvonne Chang, Modernism and the Nativist Resistance, 2-3

8o Reynaud, A City, 22
} 
coming-of-age film which followed the life of a young rebellious man. Growing Up, now recognized as one of the founding works of New Taiwanese Cinema, was itself based on a short story by young female novelist Chu Tien-wen, who would later write treatments alongside Wu for several of Hou's films, including City.

The burgeoning "Nativist Literature" (hsiang-t'u wen-hsueh) ${ }^{81}$ movement in 1970s Taiwan, spearheaded by popular writers like Huang Chun-ming, had a profound effect on filmmakers like Hou in the 1980 s. $^{82}$ In 1983 , Wu Nien-jen wrote three screenplays inspired by Huang's short stories, much of which detailed the previously untouched subject of daily life of farmers, workers, prostitutes, and small businessmen. ${ }^{83}$ Although the Kuomintang had labeled this genre as "worker-peasantsoldier" literature, an allusion to communist literary philosophy, the added attention only seemed to increase its popularity, especially with the emerging tangwai ("out-ofparty") political movement. 84

These "Nativist" literary representations of Taiwan often valorized rural life over the corrupt and globalized metropolis, and focused on the experience of native-born Taiwanese of lower socio-economic status. ${ }^{85}$ Huang Chun-ming's short story, "The Taste of Apples," for example, was published in 1972 and depicted life in 1950s Taiwan. Apples tells the story of a working-class southern Taiwanese man names Jiang Ah-fa who moves to north to urban Taipei with his family of six. One day, Jiang is hit by a limousine while riding his bicycle to work, and is hospitalized because his leg is broken.

\footnotetext{
${ }^{81}$ Literally, "Country (rural)-soil Literature."

82 A new edition of the Chinese translation of Orphan of Asia was published during this time as well.

83 Gold, "Civil Society," 61.

84 Ibid., 61

85 The Kuomintang officials and other mainlander immigrants were often associated with wealth, as many were involved in business and came from financial hubs like Shanghai.
} 
The family is initially devastated, for they could barely gather money for their children's school fees. One daughter contemplates leaving the family to work as a maid in order to lessen the Jiang's financial burden. However, it is revealed that the limousine belonged to an American military officer (many American officers served as advisers for the Kuomintang in 1950s Taiwan), and "Colonel Grey" takes full responsibility for the accident, compensating the family with a large sum of money and food. The Colonel also offers to send their youngest daughter, a deaf-mute, to a special school in America. The family is overcome with emotion in the hospital ward, and Ah-fa uncontrollably exclaims, "Thank you, thank you, I'm sorry, I'm sorry." The story ends as the family members discuss their strange predicament, and how they are now better off because of Ah-fa's accident. They munch on sweet apples that the colonel gives them, each a luxurious commodity worth four kilos of rice.

Wu Nien-jen, one of the principal writers for City of Sadness, noted that,

Before, most writers were influenced by European or American writers. After the 1970, they turned their heads to Taiwanese subjects. [Under Huang Chun-ming's] influence, we came to believe that we had to pull the film industry into our world, instead of melodramas from the West. 86

Wu's distinction between "melodramas from the West" and "our world" is crucial. Although it is unclear if $\mathrm{Wu}$ implied that the native literature from which he drew inspiration held something essentially "Taiwanese," there is no doubt that he recognized a growing trend in Taiwanese art that prioritized Taiwan as a setting, and the people who inhabited it as central characters. In 1970 s and 80s Taiwan, many Taiwanese artists and critics, despite being labeled undeveloped or crass by the state, thought they could

\footnotetext{
${ }^{86}$ Emphasis mine. Reynaud, A City, 22-23
} 
accurately (as opposed to the state) represent unique Taiwanese identities, or "ways-oflife.”

Given the influence Nativist writers had over Wu Nien-jen, it is certainly ironic that the very studios producing $\mathrm{Wu}$ and Hou's films were founded by the semi-colonial Kuomintang government. By the mid-1980s, tangwai activists began to succeed in pressuring the Kuomintang to adopt reforms that allowed for more political diversity. In 1986 the Democratic Progressive Party was founded, despite being technically illegal under martial law. DPP candidates were allowed to field candidates in the 1986 Legislative elections, and martial law was rescinded a year later. After President Chiang Ching-kuo (Chiang Kai-shek's son) died in 1988, Lee Teng-hui was selected by the Kuomintang as interim president, and he presided over further indigenization of the Kuomintang, and the final set of reforms that would see Taiwan released from singleparty rule. The first free elections took place in 1996, and Lee was again elected, this time by popular vote. One reason for Lee's popularity was his insistence on illuminating the crimes committed by the Kuomintang in Taiwan. In 1990, he appointed a committee to investigate the February $28^{\text {th }}$ (1947) Incident, which I described briefly in Chapter Two. The committee followed up its investigation by publishing a report in 1992. Lee also met with family members of the victims of the massacre, and the magistrate of Chia-yi County erected a memorial monument to those killed. 87

Just as Taiwan began its democratic transition from over forty years of authoritarian rule, A City of Sadness was released on October 21, 1989, in Taiwan to

87 Gold, "Civil Society," 62-63 
popular acclaim and box office success. It was the first film to depict the Kuomintang's oppressive regime and the February 28th Incident.

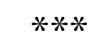

A City of Sadness chronicles the turbulent lives of the Lin family during the interregnum between 1945, when the Japanese military surrendered Taiwan to the Chinese Nationalists (Kuomintang), and 1949, when the Kuomintang and their supporters fled the mainland in the wake of civil war with the Communist Party. The film is largely set in the village of Jiufen, near Keelung City. The film begins by introducing a large cast of characters. The patriarch of the Lin family, Ah-lu, has entrusted leadership of the family to Wen-Heung, the eldest of four brothers. Wenheung opens a family owned nightclub-restaurant named "Little Shanghai" at the beginning of the film, ostensibly to celebrate Taiwan's "re-unification" with the mainland. Wen-Sen is the second brother, a doctor who has gone missing ever since being sent as a military physician to the Philippines during the war. Wen-liang, the third brother, served as a translator for the Japanese military in Shanghai, and having been captured and tortured by the Kuomintang, suffered a nervous breakdown and was sent back to Taiwan. Wen-ching, the youngest, is deaf and mute, and works as a photographer. Wen-ching communicates with others through gestures and written Chinese on a personal notepad, which almost always appears to the audience in separate stills as text on the screen. 88

Once Wen-liang recovers, he becomes involved with some old acquaintances from Shanghai in illicit drug smuggling and money forging operations. Wen-heung

${ }^{88}$ Interestingly, Wen-ching wasn't initially written as a deaf-mute character. This only came about as a later alteration because Tony Leung Chiu-wai didn't speak Hokkien fluently (he spoke Cantonese). 
becomes aware of this and chastises Wen-liang, forbidding him from continuing the activities. However, the Shanghai mobsters are displeased with the brothers' lack of commitment, and decide to report them to the Kuomintang authorities through the "Traitors Punishment Act." Wen-liang, though only a minor player in the illegal operations, is eventually seized by military police, detained and tortured. By the time he is released and returned home, he has already permanently lost his sanity.

Around this time the February 28th Incident occurs, which is revealed to the audience as a group of characters read and discuss the morning newspaper. Chen $\mathrm{Yi}$, the Kuomintang's Chief Executive of Taiwan, announces marshal law, beginning a campaign to suppress and detain "insurrectionists". Wen-ching and his close friend Kuan-rong are soon notified that authorities have targeted them, and while Kuan-rong manages to escape into the mountains to join a rebel group and oppose the Kuomintang, Wen-ching is captured and detained. Wen-ching returns home after a brief period of detainment. Upon returning, Wen-ching visits Kuan-rong in the mountains and professes his newfound desire to join the rebel cause. However, Wen-ching was not fully aware of risks involved, for his cellmates were actually being led away to be executed by firing squad, but Wen-ching couldn't hear the gunshots. Kuan-rong seems to intuit this, and after an argument carried out via Wen-ching's notepad, Kuan-rong urges him to go home and that he marry Hinome, Kuan-rong's sister and Wen-ching's romantic interest. Wen-ching reluctantly complies.

One night, after an ambiguous passage of time, Wen-heung and his concubine's brother Ah-Chia get into an altercation with the Shanghai mobsters at a gambling den, and Wen-heung is shot dead. The Lin family thus becomes completely reliant on the 
deaf and mute Wen-ching. After Wen-heung's funeral, Wen-Ching and Hinome are married in the Lin family home. Soon, Hinome gives birth to their child, Ah-Chien. Wen-ching's new family provides financial support to Kuan-rong's rebel group, but the rebels are soon surrounded and rooted out by Kuomintang secret police. The rebels are executed, but one manages to escape and writes a letter warning Wen-ching and urging him to leave town. However, a few days later (possibly through flashback), it is revealed that Wen-ching has also been captured, and his fate unknown. The film ends with the elderly Ah-lu and the mentally lost Wen-liang sitting together at their round dining table and eating silently. The trajectory of the Lin family's path to ruin is recalled in a diary form by Hinome, the film's narrator.

Like Orphan of Asia, City's key motifs are failed assimilation, cultural rootlessness, and oppression. City is a spiritual successor to Orphan because it depicts the Chinese Nationalist administration as an extension of Taiwanese misfortunes under colonial government, as seen primarily through the fate of the Lin brothers. In part one of my analysis, I explore two main points of similarity between Orphan and City. First, both works highlight the destruction of the family at the hands of government forces and policies. There is a kind of equivocation of the oppressive "state apparatus" of both Japanese and Chinese governments, making them "blend together" figuratively and literally (some Japanese experts were re-hired by the Kuomintang). Second, in their representations of Taiwanese society under colonial rule, both Orphan and City present the colonial state and the family (and individual) as inhabiting a necessarily antagonistic 
relationship. In part two, I discuss the relation between art and historical narrative, and show why Orphan and City are "foundational" post-national works.

\section{Part One: Comparing City to Orphan}

To its credit, the Chinese Nationalist government, in the spirit of Sun Yat-sen's goals of local self-government through elections, sought to increase Taiwanese political representation. Chen $\mathrm{Yi}$, against the opinions of many advisers, ordered officials to draft a plan for "establishing popular elections for district, municipal, and provincial officials by 1950."89 In the elections of April 15, 1946, 523 Taiwanese were elected to district and city councils, as opposed to just 179 in 1945 under the Japanese. Similarly, there was a significant increase in Taiwanese elected to small city and town councils, from 2681 in 1944, to 7771 in 1946. A provincial assembly was formed during this time as well, the first in Taiwan's history. 90

However, in Provincial Council interpellations there emerged heated arguments between Taiwanese and mainland representatives. Many complaints centered on the government's reluctance to fulfill public demands and employ more Taiwanese in government positions, often due to their lack of fluency in Mandarin. Council member Kuo kuo-chi, voicing a common grievance, declared that "it is absolutely intolerable that the government refuses to employ Taiwanese on the pretext that, unversed in Mandarin, they are ignorant of Chinese."91 Some council members also pointed out that the Kuomintang government had employed Japanese personnel for jobs they believed

\footnotetext{
89 Lai Tse-han, Ramon H. Myers, and Wuo Wei, A Tragic Beginning: The Taiwan Uprising of February 28, 1947 (Stanford University Press: 1991), 68

90 Ibid., 68

${ }^{91}$ Ibid., 70
} 
should have gone to Taiwanese. ${ }^{2}$ Chen Yi justified this at the interpellations by claiming that "because we had to have some governance, and because of the shortage of high quality personnel, it was difficult for us to accept the resignation of Japanese officials. Thus, we were compelled to employ the Japanese."93 Looking back on the early Kuomintang years, Wu Zhuoliu noted in his memoir that although initially hopeful for greater political opportunity under Kuomintang rule, Taiwanese intellectuals "strongly felt that after retrocession, the new conditions were no different than under Japanese rule, and they were greatly disappointed." 94

Like Hu Taiming and his half-brother, the Lin brothers are destroyed by the combination of Japanese and Chinese involvement in Taiwan. Lin Wen-heung has the potential to adapt well to the new regime at the start of the film, and he clearly wishes to curry favor with the local waishengren by naming his restaurant "Little Shanghai" and hosting local Shanghainese mobsters. However, such efforts are undone when Wenheung is forced to defend his delinquent brother Wen-liang, and both men are targeted by mainland mobsters and officials, who collaborate to frame the brothers under the Traitors Punishment Act. Wen-heung is killed in an altercation with the mobsters, and Wen-liang is only returned from a Kuomintang prison after he is mentally broken. Eventually, Hinomi's narration reveals that Wen-ching is also missing, likely "disappeared" by military police. The final scene of the film consists of Ah-lu and the now imbecilic Wen-liang seated alone at a round dinner table, symbols of a ruined and empty household.

\footnotetext{
92 Ibid., 70

93 Ibid., 70

94 Ibid., p. 67
} 
Both films position the colonial state and the family/individual in an antagonistic relationship. Wen-liang and Taiming both suffer mental breakdowns, and the Japanese and Kuomintang governments are both involved directly in the death of brothers in both families. Taiming's mother falls ill and dies soon after a stressful encounter with her eldest son Zhigang, a village arbitrator working for the Japanese, who scolded and threatened her for hiding rice during a period of strict rationing. 95 Taiming's grandfather also dies after a stressful family feud over property partition (prompted by the Japanese government's encroachment onto family property). Ah-lu, the patriarch of the Lin family in City, endures the death of one son, while two others go missing, leaving only Wen-liang. One particular scene shows Ah-lu lambasting Kuomintang military police as they barge into the Lin home in the middle of the night looking to arrest Wen-heung and Wen-liang. However, the old man's defense of his family's integrity and good conduct falls on deaf ears as soldiers scramble past him to search the house.

$\mathrm{Mr}$. Wu (played by Wu Nien-jen), a local teacher and friend of Kuan-rong, criticizes garrison commander Chen Yi for enriching his mainlander officials at the expense of the Taiwanese, claiming that he had "no hope" for Taiwan under Chen's government. The incompatibility of Taiwanese and Chinese is also conveyed less directly through linguistic barriers as well: the brothers have to use interpreters when dealing with the mobsters because although both parties are speaking the same language, they use different dialects. Later, Lin Wen-ching, the deaf-mute, is mistaken for a mainland Chinese by some rebel ruffians on a train due to his inability to speak 
Taiwanese. Taiming and the Lins are similar in that language and accent plays a key role in their misfortune.

City succeeds Orphan in a temporal sense too, for the film opens on August 15, 1945 to the radio broadcast of Emperor Hirohito's announcement of Japan's unconditional surrender to the Allied powers. This historic event marked the first time the Emperor spoke to his subjects. The Emperor's discomfort with defeat, the modern medium, and the direct address to his empire was reflected in his stilted speech. ${ }^{96}$ The speech was given in an archaic classical Japanese which most of his subjects, including Japanese on the mainland but especially Taiwanese on the colonial periphery, wouldn't have fully understood. ${ }^{97}$ In the background, Lin Wen-heung is seen nervously smoking a cigarette as he listens, both to the radio and the sounds of his concubine giving birth in the other room. The lights flicker on, and Lin covers the bulb with a cloth to avoid attracting attention from potential air raids. As the woman's moaning grows louder, a mid-wife announces that a baby boy, Lin Guang-ming ("Light") is born. The birth of "Light" is deeply ironic considering how much the film concerns itself with opacity and loss: from Japan's loss of Taiwan to the Kuomintang's loss of mainland China. "Light" also begs comparison with "Taiming," whose name literally translates as "too bright," but could also reference the Ming dynasty (the last "Han Chinese" dynasty, before the Manchu Qing).

Although the few Japanese characters in the film appear in flashback, traces of Japanese culture are littered everywhere. The cameraman taking the Lin family's

\footnotetext{
${ }^{96}$ John W. Dower. Embracing Defeat: Japan in the Wake of World War Two (W.W. Norton \& Company, 1999), 34. See 32-39 for more on the speech's reception.

97 Reynaud, A City, 10
} 
portrait at the beginning of the film speaks in Japanese, and Japanese is peppered throughout the film in various Hokkien phrases. Early on, there is a heated discussion between several intellectuals about the inconvenience of the new Republic of China flag: they complained that people were being penalized for hanging the flag "upside down." This kind of issue never happened with the Japanese flag because it looked the same "whichever way you hung it up." Today, Mr. Wu says, the Japanese flags provide another convenience in that they can be made into children's clothes. In a flashback, Hinome's Japanese friend Shisuki leaves behind a kimono, sword, and poems from her Shisuki's brother who disappeared in the war. Although this short scene emanates a delicate tranquility juxtaposed to the rest of the film, the stilted and formal behavior between friends nonetheless indicates a strong sense of hierarchy between Japanese and Taiwanese. Through the flashback, City represents the Japanese past as a source of existential confusion for the Taiwanese characters, who look back almost with nostalgia, despite the uncomfortable recognition of their status as "lower" subjects at the time. Despite the fact that Taiwan was "returned" to the "rightful" Chinese government, this lingering impression of Taiwanese as colonial subjects does not subside.

\section{Part Two: Art and Historical Narrative}

In the first chapter, I briefly discussed "Taiwan Consciousness," a term used by many scholars involved in the discourses on Taiwan literature and its relation to a unique Taiwanese cultural identity. Earlier in this chapter I also mentioned that Wu Nien-jen, who co-wrote City, was inspired by native Taiwanese authors of the hsiang-tu movement. Now, I provide one scholar's critique of "Nativist" writers' and critics' politics, and discuss the implications in relation to City. This critique shows that the 
politics of an "independent" Taiwan heavily influenced certain literary figures' definitions of what "qualified" as truly "Taiwanese" art. These definitions were tinctured with ethnic-essentialist suppositions, and would have left out A City of Sadness, a film directed by a mainland-immigrant (yet critical of the Kuomintang) that is today widely regarded a masterpiece of Taiwanese cinema.

Tang Xiaobing's essay, “On the Concept of Taiwan Literature," examines the contentious Nativist Literature debates in Taiwan during the 1970s and 80s. Tang adroitly juxtaposed the arguments of various pro-unification and separatist literary scholars. Chen Fangming, for example, is a prominent pro-independence critic, historian, and activist who wrote an essay in 1984 titled, "Issues Concerning the Nativization of Taiwan Literature at the Present Stage," in which he targeted the "chauvinistic Chinese consciousness" of Chen Yingzhen, a native-born Taiwanese antiseparatist critic. For Chen Fangming, the tension between grassroots resistance and the Kuomintang's ideological apparatus represents the driving force from which he traces the formation of a unique literature (and identity) of Taiwan. 98

Tang distills four points visible in the arguments of anti-unification literary scholars like Chen Fangming and Peng Ruijin. First, both emphasize that Taiwan literature should be rooted in the "land and people" of Taiwan, and be concerned primarily with Taiwan's social condition. The nativist literature debate thus assumed a clearly ethno-nationalist tincture, which in turn seeped into debates on "Taiwanese identity." Second, in the scholars' endorsement of democracy, the nativist movement put popular pressure on the Kuomintang, and tended to depict the mainland as a

${ }_{98}$ Tang, "On the Concept of Taiwan Literature," 62-64 
"monolithic, intransient, totalitarian regime." The search for a "Taiwanese literature" in this context was "unequivocally equated" with the defense of liberty and democracy. Third, and perhaps most dangerously, self-determination and nativism demanded that the history of Taiwan be re-interpreted in order to center on the native subject in order to "reconstruct" his self-consciousness. The assumption that there is something in history to "reconstruct," with regards to an identity of the people of Taiwan, relies completely on the kind of essentialist, mythic view of history that has been employed in official nation-building projects. Chen Fangming's promotion of this "native subjectivity" (zhuti xing) nonetheless saturated literary circles in the 1990s. Finally, Peng and Chen's conception of Taiwan literature contains several clear categorical biases. For example, they define this literature largely as a record of the "painful history" of the oppression of people on Taiwan. Because of this, the authors associated with work that deals with the colonial period seem fated to represent a perpetual "victim consciousness." Peng and Chen also tended to valorize the "idyllic" rural over urban settings. Tang concludes that within this Nativist discourse, "literature (became) a sacred enterprise because it (was) called on to buttress an overdetermined myth of origin and destiny."99

Tang writes,

The specific agenda articulated through an idealized notion of Taiwan literature is to invent a distinct and usable cultural tradition to serve the cause of Taiwan's independence. Such a reclaiming of an obscured tradition or unique spiritual heritage has been a common and potent strategy in modern nationalism and colonialism worldwide. The objective is to insinuate and fortify a new sense of collective identity, often through instilling a victim consciousness, so as to lend cultural and moral legitimacy to the pursuit of political self -determination. ${ }^{100}$

99 Ibid., p. 64

${ }^{100}$ Emphases mine. Ibid., 61 
Chen Fangming characterized literature by Taiwanese as necessarily evoking a "spirit of resistance and critique." ${ }^{101}$ Resistance and critique of oppressive regimes are indeed present in many seminal works of Taiwanese fiction, like Orphan of Asia and the 1989 film A City of Sadness. However, Chen's conceptualization of Taiwanese literature and its historical formation is crippled by the unconcealed influence of separatist politics and use of ethno-nationalist language. His interpretation not only avoids subtle interpretations of works like Orphan, but also conceives of the Taiwanese consciousness in an almost comically narrow fashion. What should we make of Chinese immigrant, Hakka, indigenous, and urban Taiwanese literatures, for example? If their narratives do not center on "history of oppression," does that mean they are somehow less representative of a Taiwanese consciousness? It doesn't, because even in an historical fiction like City that is exclusively about Kuomintang oppression, its depiction of said oppression does not equate to an expression of Chen Fangming's idea of "native subjectivity." In other words, in City there is no essentialist "Taiwanese nationalism," nor nascent "Nation" of any sort. There is no indication that the Lin family or other characters negatively affected by the Kuomintang felt oppressed because their national pride was being trampled on. In fact, I find City interesting precisely because although it contains all the ingredients for an anti-imperialist interpretation of Taiwan's history, City's narrative construction keeps it from descending into a one-sided diatribe against the Kuomintang. It instead yields direct comparisons to Orphan of Asia in its insistence on the destructiveness of identity politics. It does not promote a separate nationalism in response to Kuomintang, and instead rejects this conceptualization altogether as inadequate in the effort to define the people of Taiwan.

${ }^{101}$ Ibid., 68 
Although City was billed as a film "about" the February 28 Incident and was popular with the public, one academic review surmised that initially "critics [...] were ambivalent. Since the Incident is not shown as a violent on-screen spectacle, many people felt the film was politically ambiguous (i.e. did not take a strong enough stand against the Kuomintang of the time) and historically inaccurate." The same review added that "(other critics) faulted the film for its hermeticism, its 'hard to follow' style." ${ }^{102}$ I believe City's narrative opacity and difficulty exist in order to highlight the difficult relationship between the people of Taiwan and the oppressive government that claimed them as subjects. Hou's elliptical arc in City echoes Wu Zhuoliu's manipulation of time in Orphan. Orphan is narrated in a disjunctive and stilted fashion, the passing of time rarely explicitly stated and dates are never given, a touch that reflected the uncertain circumstances in which $\mathrm{Wu}$ wrote.

Differences in medium aside, Hou's style takes narrative disruption to even greater heights. His frequent use of flashback interrupts the narrative flow in a more disconcerting fashion, which often leads to characters appearing in radically different circumstances with little or no immediate explanation given. This technique forces the audience to reconstruct the plot chronologically after scenes are presented. Hou's technique is similar to Joseph Conrad's "delayed decoding," which is showcased in his seminal novel Heart of Darkness. This technique is exemplified when Marlow recounts a native attack on his steamship as they move upriver:

The end of what appeared a long cane clattered round and knocked over a little camp-stool ... my feet felt so warm and wet that I had to look down. The man had rolled on his back and stared straight up at me; both his hands clutched that cane.

\footnotetext{
102 Eileen Cheng-yin Chow, “A City of Sadness," Harvard Faculty of the Arts and Sciences. Course: Screening Modern China, Accessed 25 March 2017: http://sites.fas.harvard.edu/ chlit130/handouts/handouts 10/cityofsadness.html
} 
It was the shaft of a spear ... my shoes were full; a pool of blood lay very still gleaming dark-red under the wheel. ${ }^{103}$

Like Marlow, Hou's audience perceives images and sequences before they can process their significance. Literary scholar Pericles Lewis points out that although Conrad's work sometimes showed Symbolist tendencies, it ultimately "owed more to impressionism."104 Indeed, the "impressionism" of Heart of Darkness can be discerned early on in the following passage: "(to Marlow) the meaning of an episode was not inside like a kernel but outside, enveloping the tale, which brought it out only as a glow brings out a haze."105 This holds true for A City of Sadness, which dances around the issue of colonial violence during the February 28 Incident, instead relying on disappearing characters, newspaper discussions at breakfast, gunshots from executions taking place out of frame, and hazy chase scenes with police pursuing rebels through the mountains. The combination of these events and City's dense, obfuscated narrative thus illustrates the mood of dull anxiety and confusion of late-1940s Taiwan.

Film scholar Berenice Reynaud also characterized Hou's style as a "form of Impressionism," citing an interview with Hou in which he discussed his preferred method of conveying time and unfolding plot:

We (including screenwriters Wu Nien-jen and Chu Tien-wen) laid the basis [of the narrative structure] by reconstructing the feelings and emotions of that time ... creating an atmosphere ... therefore producing a subjective view towards this whole period of time ... then they built up the characters, and depending on

\footnotetext{
103 Joseph Conrad, Heart of Darkness, ed. Paul Moliken, Sondra Y. Abel, Lisa M. Miller (Prestwick House: 2005), 45

104 Pericles Lewis, "Heart of Darkness," The Modernism Lab at Yale University. Accessed 26 March 2017: https://modernism.research.yale.edu/wiki/index.php/Heart of Darkness\#cite note-1
} 
their importance, they poured details gathered through their historical research into them -- then re-started all over again ... Since so many things happen in the background, we'd rather use flashbacks than a linear structure, and introduce [the spectator to the story] through a multiplicity of details. In the editing process, it became unimportant to define what was reality and what was flashback; I like to blur the line between the two. ${ }^{106}$

Of the film, Hou recounted, seemingly as a disclaimer:

It didn't really matter whether or not we made a film taking place in modern times or in an era none of us had experienced. I don't think, anyhow, that A City is a realistic representation of what happened -- it is my subjective view, my "imitation" of that time, it remains an imaginary world. 107

Despite this, I believe that $\mathrm{Hou}, \mathrm{Wu}$, and Chu's creation in City provides us with a historical representation, no more or less valuable than a "professional history," though obviously different in mode. Hou seemed to have wanted to defuse some of the criticism over his film's historical accuracy with this claim, but his notion of the film being an "imitation" of an "objectively-having-existed" set of societal conditions (e.g. Kuomintang oppression of native Taiwanese during the February 28 Incident) applies to all professional histories as well. The philosopher of history Frank Ankersmit published "In Defense of Subjectivity" in 1989, in which he proposes that we reconsider the "objective" and "subjective" in our evaluation of historical work.

Ankersmit argues that the notion that good history consists of an account of factual data, ostensibly devoid of any moral or political influence, is not only narrow and hypocritical, but impossible. Take, for example, the classic notion that historians should be "objective" when recounting the past, in order that their "subjectivity" not "add" to

106 Emphases mine. Reynaud, A City, 9-10

${ }_{107}$ Hou Hsiao-hsien Interview, Oct. 1989, quoted in Reynaud, A City, 24 
the "object" in question. Although many historians often take for granted the "subjective" biases of competing historical schools of thought, writing styles, topic preferences, or even "individual stupidity," they paradoxically demonstrate, he suggests, a particular sensitivity to the presence of political or moral leanings that may influence historical conclusions within a given work. ${ }^{108} \mathrm{He}$ instead suggests that the problem "might well be that political and moral values are a way in which historical truth may sometimes manifest itself and vice versa." 109 The way professional history is actually written, he points out, resembles the way a portrait painting is created.

The physical appearance of the sitter for a portrait as presented by a photograph corresponds to a mere "shadow," a mere "abstraction," so to speak, which is constructed out of all the "representeds" having their counterpart in the representations of the sitter produced by portrait painters (or even by all those people in his entourage knowing him sufficiently well to have formed for themselves an opinion about him). This is where the objectivity of so-called objective reality may so dangerously deceive us. For representations are truly basic, whereas the things of "objective reality" are mere constructions, abstract truncations of concrete representations. Hence, as in the case of the narrative representation of the past, pictorial representation and what I represents logically depend upon each other and owe their existence to each other. ${ }^{110}$

The key point that Ankersmit emphasizes is the mutual dependence between historian/artist (representor) and "history/object" (represented). For example, if we consider two historical things, Karl Marx and "the labor movement," we immediately see two separate categories of historical object. Marx can be said to be a concrete, identifiable human being who existed between 1818 and 1883. There are also histories written about Marx. "The labor movement," however, has a different kind of existence than Marx the individual. The historical existence of a labor movement (as opposed to

\footnotetext{
${ }^{108}$ Frank Ankersmit, "In Praise of Subjectivity," in The Ethics of History, ed. David Carr, Thomas R. Flynn, Rudolf A. Makkreel (Evanston, IL: Northwestern University Press), 4 109 Ibid., 5

${ }^{110}$ Ibid., 11
} 
the individual named Karl Marx) thus relies completely on its representations by historians. Ankersmit suggests that, since the past cannot be re-accessed, historical representations substitute for reality. "Historical reality" as it is known in the present thus only ever refers to the understandings reached through narrative constructions from historians.

What does this have to do with City and Hou's representation of the February 28 Incident? In the review mentioned earlier, we saw that some critics believed City to be historically inaccurate because its representation did not contain scenes directly depicting the massive orgy of state-sponsored violence that affected thousands of people. In my discussion earlier of the Nativist literature debate, we saw that several prominent scholars asserted that only a literature which acknowledges Taiwan's "history of oppression" could be said to accurately represent a "Taiwanese consciousness." I bring up Ankersmit's piece because I perceive an excess of normative judgment and a dearth of historical sensitivity in critiques of works like City and Orphan that sought to analyze them through a framework relying heavily on two things; a limited conception of what the people of Taiwan were or could be (i.e. either a subjected populace or an independent nation), and the prevailing conditions of Cold War politics and the looming threat of China under the PRC (which seemed to make the definition of a "Taiwanese identity" an urgent project).

If A City of Sadness was considered a poor historical representation because of its indirect, "impressionistic" way of dealing with a historical event that was widely considered to be a tragedy, would it follow, then, that a film depicting mass violence with clear demarcations of victim and perpetrators is historically accurate? Of course 
not; it would still be over-simplistic. If anything, gratuitous depictions of the February 28 Incident violence and its attendant victim-perpetrator dynamic might evoke a more visceral emotional response, but at the expense of subtlety. Simple teleological narratives and black-and-white emotional appeals seem more a hallmark of mythicpolitical accounts than historical ones. Therefore, I believe that when scholars such as Chen Fang-ming argue (using a "historical" approach) for the construction of a national identity through literature, they are attempting to trace a construct ("Taiwanese consciousness") from its "roots" (oppression) to a later state (the attempt to shake off oppression, in the scholar's own later time), their conclusions often devolve into mythic caricatures of historical populations and their sensibilities. ${ }^{111}$

Unlike most written works, film is a necessarily collaborative effort. Part of why City is important is because it is a historical fiction of Taiwan's colonial past that relies on a plurality of perspectives. Moreover, it was a collaboration between writers of native-Taiwanese descent (Wu Nien-jen), second-generation waishengren (Chu Tienwen), and a waishengren director (Hou Hsiao-hsien). The resulting cultural product does not fit into a strict "native-Taiwanese" versus "mainlander" binary, just as the film's narrative resists an "easy" representation of colonial violence. Both Orphan of Asia and A City of Sadness were forms of cultural protest: they criticize both the oppressive colonial governments and circumstances of their time, but in their depictions of Taiwanese life, they were also painfully aware of the derived nature of Taiwanese culture and identity. Accordingly, the depiction of a "Taiwanese nation" having a history independent of (or "against”) its colonial oppressors is problematic: more often than not,

\footnotetext{
${ }^{111}$ For instance, when Chen suggests that Native literature can only be written by "native-born" Taiwanese. By this logic, the China-born Hou Hsiao-hsien wouldn't be making "native Taiwanese" film, and wouldn't be representing a "Taiwanese consciousness" in his work.
} 
the people of Taiwan have sought some kind of accommodation with both Japanese and Kuomintang governments, and both governments, despite their use of violence, also undeniably sought the betterment of the people of Taiwan in various respects. In highlighting their treatment of the cultural and political complexities of Taiwanese life under Japanese and Kuomintang, I have shown that Orphan of Asia and A City of Sadness display a post-national frame of mind. This frame of mind is one that cannot convey a colonial Taiwanese identity as clearly demarcated against Chinese or Japanese identities and influences, but rather situates Taiwanese in a confused, liminal state, between resistance and assimilation. In recent years, historical fiction in cinema has become popular in Taiwan, and has built on the kind of post-national framework present in works like Orphan and City. Next, I show how representations of Taiwanese life and treatment of the colonial era have changed in democratized Taiwan. 


\title{
Chapter Four
}

\section{Nostalgia Machine: Reconciling Past and Present in Wei Te-}

\author{
sheng's films
}

To fully dismantle the nationalist legacy, one first must acquire a post-nationalist vision and free oneself of nationalist passion and logic, which [...] does not seem to be the motivation behind the advocacy of an independent Taiwan literature in general and Peng (Rui-jin)'s positioning of Taiwan literature in particular.

-Tang Xiaobing, "On the Concept of Taiwan Literature" 112

I have shown in preceding chapters that the articulation of Taiwanese identities or "consciousness" in art does not rely on the construction of a Taiwanese "nationalism," despite the tendency of some Taiwanese scholars to employ politicized interpretations. How do we articulate a "post-nationalist vision" of Taiwanese life, as Tang puts it? To answer this question, I look to cinema once more, and to Taiwanese director Wei Tesheng's recent films Cape No. 7 (2008) and Seediq Bale (2011) in particular. In this chapter, I discuss Wei's mission in cinema, and how he distances from (but does not outright reject) the traditional historical perspectives of the dominant "Chinese" ethnicity in favor of native born Taiwanese (including Hakka, and aboriginal peoples). The images of life in present-day and historical Taiwan present in Wei's films builds on, but also deviates from, the post-nationalist foundations of Orphan and City. To be specific, I interpret Wei as a proponent of historical "forgetting," for his films are fictional representations of the past which seek to resolve types of historical traumas between ethnicities and identities through catharsis.

${ }_{112}$ Tang, "On the Concept of Taiwan Literature,” 77 
The forgetting of history has been cited by many philosophers and historians as a necessary process in maintaining productivity in the present. Friedrich Nietzsche, in his second Untimely Meditation, proposed that an "active forgetting" of history was necessary for healthy life in the present. In a similar vein, Ernest Renan suggested that collectively, the individuals that constitute a nation "have forgotten many things." Forgetting of the past, or "historical error," Renan held, "is an essential factor in the creation of a nation and it is for this reason that the progress of historical studies often poses a threat to nationality" (emphases mine). ${ }^{113}$ According to Renan, historical inquiry shed light on the violent origins of political formations. Later I bring up Berber Bevernage's work on truth commissions to show that the acts of remembering and forgetting the past have complex political implications and are often in tension with each other. Does history pose a threat to nationality? If so, does historical fiction pose a threat as well? Cape and Seediq are historical fictions that seek a degree of resolution with regard to past events, and I show that they in fact are antithetical to "nationbuilding;" for although the films deconstruct ethnic identities and colonial relations of the past, they do not "use" history to create an image of present-day Taiwan as a nation unified by its shared suffering. Before introducing the films and expanding on my argument, however, a review of the content and contexts of Wei's films is necessary.

Born in 1967 , Wei belonged to the generation that came of age as Taiwan was released from martial law and transitioned to a democratic system under Lee Teng-hui. Wei worked as an assistant director under Taiwanese director Edward Yang, a contemporary of Hou Hsiao-hsien and one of the leaders of Taiwanese New Wave 
Cinema. Wei gathered funds from odd jobs to make small-scale films in the mid-late 1990s, but did not complete any breakout pieces before 2008 with Cape No.7, his first full-length feature. Today Cape is widely believed to have initiated a resurgence in Taiwanese cinema, and it also remains the second highest grossing film in Taiwan behind 1997's Titanic. Wei noted in a 2016 interview that his later films Seediq Bale and Kano, both of which enjoyed considerable success (Seediq is the second top grossing domestic film), would not have been possible without Cape's initial success. ${ }^{114} 115$ Filming Cape was a risk for then virtually unknown Wei, and though he worked with a small budget of approximately US $\$ 1.5$ million, he only managed to do so by cobbling together loans from banks, family, friends, and funds provided by the Government Information Office. The film turned out to be a hit, and made up its budget by ten-fold in the first ten weeks in theaters. Besides the significant impact Wei's films have on current domestic Taiwanese arts and popular culture, they are interesting because of their heavy engagement with the Japanese colonial period.

In an interview with the New York Times in 2008, Wei claims to have always been "interested in history, and bringing the social values and cultural perspectives of local Taiwanese people into (his films)." 116 In another interview, he claimed that although the work of directing was difficult, he felt a sense of duty to tell stories. Seediq Bale, for example, tells the story of the 1930 Musha uprising, a historical event that Wei

\footnotetext{
114 Wei Te-sheng, interview by Lin Chi-hsun, "Wei Te-sheng Rediscovers Cape No. 7, With Plans to adapt it into a Theater Production to thank his fans. 'Even if it costs me more than it earns, it should be done nonetheless!'” China Times, 3 September 2016. Accessed 30 March 2017 at:

http://www.chinatimes.com/newspapers/20160903000664-260116 115 Seediq Bale, behind the scenes content. Accessed 30 March 2017 at: https://www.youtube.com/watch?v=mc2FpmoHeto ${ }^{116}$ Wei Te Sheng, interview by Sonia Kolesnikov-Jessop, “The director Wei Te Sheng's Long Road to Fame," The New York Times, 7 November 2008. Accessed 30 March 2017 at: http://www.nytimes.com/2008/11/07/arts/o7iht-jessop.html
} 
believed more modern audiences should know about. ${ }^{117}$ Seediq Bale was originally released in two parts, The Sun Flag, and The Rainbow Bridge, with a total running time of four-and-a-half hours, though they were later combined in an international cut, which runs at two-and-a-half. On the surface, Cape and Seediq appear to be two very different types of film: the former is a romantic comedy, and the latter is an actionoriented historical epic. However, the dramatic effect of both films relies heavily on the use of "history" to encourage viewers of the present to (re)consider Taiwan's historical past.

\section{Cape No.7}

The stage is set in December 1945. A Japanese teacher boards a ship returning to Japan, and writes a series of seven love letters addressed to a young woman named Tomoko, his student and lover. The film cuts to modern-day Taipei. A-ga, an unsuccessful rock musician, smashes his guitar and curses Taipei before returning to Hengchun, his hometown at the southern tip of Taiwan. A-ga's stepfather Hong Guorong, the town council chair, arranges a temporary job for A-ga at the post office. However, the rebellious A-ga neglects his duties, and prefers to slack off by the sea side. One day, out of curiosity, A-ga illegally opens a parcel to find a lacquered box containing letters written in Japanese, which he leaves in a corner of his room because he can't read them.

As this happens, a hotel in nearby Kenting invites Japanese singer Kousuke Atari to perform at the nearby beach. After a heated argument about "globalization" and a lack of opportunities for locals, Hong persuades the hotel owner to hire a local group to

${ }_{117}$ https://www.ptt.cc/man/movie/D5E7/D5E6/DFF1/DA42/DCFA/M.1308937328.A.F87.html 
open for Atari's concert. The owner agrees, and tasks Taiwan-based Japanese translator Tomoko, part of Atari's welcoming crew, to help scout out local talent.

An audition is held in Hengchun, and a motley crew is assembled. Rauma, the guitarist, is an aboriginal police officer going through a tough divorce; Da-da, the keyboardist, is a whimsical sixth grader who performs at a local church; Frog, the drummer, works at a local motorcycle repair shop. A-ga is the reluctant vocalist and "leader" of the band. Immediately, the band encounters difficulties. The bassist is switched three times: and group eventually settles on "Malasun," a diligent salesman of Hakka descent who lingers around the hotel trying to boost sales for his kavava rice wine brand, Malasun.

At first, the band members quarrel frequently, putting their own selfish desires above the group. The group rehearses one song A-ga wrote several years ago, but as the day of the performance creeps closer, A-ga still hasn't finished writing the agreed-upon second song. Tomoko is furious and threatens to quit. As she storms out the hotel, Old Mao presents her with a relative's wedding invitation in formal, carefully prepared Japanese. Tomoko is moved by the gesture and accepts. At the wedding Tomoko imbibes too much alcohol, and ends up outside A-ga's house, drunkenly cursing his lack of resolve. A-ga, after roaming about in his characteristic lackadaisical manner, finds Tomoko crying outside his doorstep. The two embrace and overcome their mutual strife. The morning after, Tomoko wakes up in A-ga's room to find the letters at the foot of his bed. She reads them and is touched by the teacher's professions of love and longing. Tomoko discovers a note written by the teacher's daughter explaining that he died recently, and that she discovered the letters hidden in a dresser. The letters are addressed to a "Tomoko at Cape No. 7." 
Tomoko exhorts A-ga to deliver the letters as soon as possible. He complies but the address is out-of-date and he cannot find it. In the final nights before the performance, A-ga finally finishes the second song. On the morning of the performance, as the band makes final preparations, Tomoko shares a cigarette with Ming-chu, Da-da's mother. As Tomoko mentions the letters, Ming-chu reveals that the older Tomoko is actually her estranged grandmother. Tomoko receives the updated address of "Cape No. 7" and gives it to A-ga. Tomoko tells him to write her about the letters once he's delivered them, and she explains that she plans to return to Japan with Atari's entourage. A-ga instead rushes to the address, and enters the home to find an old woman at work washing some produce. He leaves the box quietly on a nearby bench, and speeds back to the concert just before it takes place. He embraces Tomoko and implores her to stay; or that he would leave with her.

A-ga and the band put on a lively performance; the first song vivacious and rockinspired, but the second song turns out to be much softer and romantic, influenced by A-ga's change of character after meeting Tomoko. Tomoko accepts A-ga's profession of love, and the crowd goes wild, requesting an encore. Unprepared, A-ga and Old Mao make an impromptu performance out of "Wild Rose," an old Japanese folk song that Old Mao heard growing up. Atari, recognizing the song, jumps in from the sidelines and joins them. As the music continues, the film cuts to the old Tomoko, who upon finishing her chores at dusk, discovers the lacquered box next to her. As she opens it and begins reading its contents, the film cuts to a flashback depicting the teacher, overcome with regret and sorrow, manages only to kneel at the ship's railing as he peers into the crowd 
gathered at the port. Tomoko, dressed in her finest garments, stands among the crowd looking on as the ship departs, and the two lock eyes just as the ship passes.

\section{Seediq Bale}

Seediq Bale follows the life of Mona Rudao, a warrior (and later chief) of the Mahebu Seediq people, who comes of age just as Japanese forces begin their occupation of Taiwan in 1895. After a series of conflicts between Mona's tribesmen and the Japanese forces, Mahebu and nearby villages are eventually occupied. Over twenty years later, the Seediq are pacified, prohibited from owning firearms and hunting game, their traditional source of sustenance. The men are forced into low-paying logging jobs, the women as house servants for the Japanese, and the children are sent to the Wushe public school. Many men turn to alcohol for succor, and become indebted to the local drugstore owner. One of the most significant changes to Seediq life is the forbiddance of face tattooing rituals. The tattoos are gender specific, and men are permitted to receive them only after killing their first enemy (headhunting). The tattoos are a sacred totem required for safe passage across the "rainbow bridge" in the afterlife.

After Mona's son gets into an altercation with a local Japanese officer, the officer refuses to accept apologies and threatens to severely punish Mona's village. Mona and his tribesmen, who have long nurtured a hatred for the oppressive Japanese, decide that war is now inevitable despite the relative peace of the last twenty years. Mona appeals to the other Seediq chieftains and schedules to attack the Japanese as they congregate on October $27^{\text {th }} 1930$ for a sports day celebration in Wushe. Mona wins over chieftains and young men from neighboring villages, despite the recognition that they may all die, because they would rather pass into the afterlife through honorable battle than continue 
to live in shame. The Wushe attack is carried out, and Japanese men, women and children are slaughtered. Several young men earn their tattoos by killing the Japanese school teacher. A Han Chinese store owner is spared, as are a few Seediq women in Japanese dress.

In the aftermath of the Wushe massacre, Japanese authorities organize a punitive force and begin aerial bombing Seediq territories, using mustard gas in defiance of the Geneva Convention. Many Seediq women and children begin to commit mass suicide in nearby forests, including Dakis Nomin, a Seediq man who had been working as a police officer under the Japanese. The Japanese succeed in winning over Seediq chieftains such as Temu Walis, a former ally of Mona, whose resolve was shaken after seeing the hanging bodies in the forest. As the Seediq force splinters, the film implies that Mona either killed his wife, or that she hanged herself. And Mona himself commits suicide soon after. Some Mahebu Seediq who survive the Japanese assaults are later attacked by Kojima, a police officer once friendly to the Seediq, but who turned hostile after his family was killed in Wushe. Years later, a hunter discovers Mona Rudao's remains in the forest, and then sees Mona leading his people across a rainbow bridge. The film ends with a narrator telling the Seediq creation story, of a man and woman born out of a gigantic tree made half of wood, and half of stone.

\section{Nostalgia, Trauma, Resolution: Comparing Cape with Seediq}

Cape is a film about the past's lingering effects in the present, and Wei used historical documents (Tomoko's letters) as a tool to intertwine past and present narratives. First of all, there are elements of the past that physically exist in Cape's present setting: the old Tomoko, the Japanese letters, and Old Mao, who often speaks in 
Japanese and sings Japanese songs from his childhood. More interesting, however, is how Wei suggests the past is meaningful for those in the present. Wei cuts back and forth between the teacher's narration of the letters and key scenes in Cape's present that evoke similar emotions. For example, in one scene the teacher writes of the heartwrenching frustration and helplessness he feels at sea, of the shame he feels at having left Tomoko, and of his longing to send her his feelings of love. He wishes a storm would "drown (him) in the waters between Japan and Taiwan," and vows "never to look at the sea again" once ashore. As the teacher continues the voice-over narration, the visual cuts to the present, to a scene of Tomoko on the beach, then to one of A-ga swimming in the sea. Here, the teacher's narration ends with a curse on the sea and the sorrow it brought him, and the next shot is of A-ga arriving late to rehearsal. Tomoko decides to quit when she discovers that A-ga has been avoiding his responsibilities yet again, a decision that then leads to her encounter with Old Mao.

The two lines of plot meet and reach a conclusion in the present, for just as A-ga and company complete a successful performance, the Old Tomoko finds and reads her letters. As Tomoko is transported back to the moment her lover's ship departed, Cape's central theme of longing is hammered in once more. Longing in this context is a longing for the past, or nostalgia. This is exhibited in different characters: Old Mao has a penchant for old Japanese folk songs, and insists that he was once a "national treasure" because of his proficiency in the yueqin. Rauma wears a necklace he calls "pearls of tears," a symbol of his undying love and longing for his wife, who separated from him. Hong Guo-rong laments the fact that the tourist industry has taken over nearby Kenting, 
and that the locals can "no longer gaze at the sea" because of the high-profile hotels and shops that have cropped up by the beach.

Somewhat like a historian, Wei melds the emotional contents of the past and present together through a set of documents/artifacts and testimonies. Of course, the letters and characters are fictional, but the effect Wei creates by incorporating a symbolic past into the film's narrative is similar. Wei's engagement with history in Cape and Seediq was deliberate: in an interview with Taiwanese media, Wei claimed that Cape's story was one about "dissolving sorrow," while Seediq Bale was about "dissolving hatred, not creating it." 118 On a somewhat sentimental note, Wei added that he was especially intrigued by an historical event in which two peoples, "one whom worshipped the sun, and one whom worshipped the rainbow" could be pitted against each other in such a vicious conflict without realizing that they "shared the same piece of sky." 119

In History, Memory, and State-Sponsored Violence, Berber Bevernage, a philosopher and theorist of history, discusses opposing conceptions of time in truth commissions and transitional justice. Bevernage claims that history is introduced into the field of transitional justice (through truth commissions) because of, not despite, an "already overabundant memory." 120 The book's first chapter is dedicated to the truth commission in Argentina following the "Dirty War" waged by right-wing state forces against left-wing guerillas between the mid-1970s to 1983. Specifically, Bevernage

${ }^{118}$ Hua jie yi han can also be translated as "dissolving regret or sadness." Hua jie can itself be translated loosely as "letting go of." Accessed 3 April, 2017:

https://www.ptt.cc/man/movie/D5E7/D5E6/DFF1/DA42/DCFA/M.1308937328.A.F87.html

119 Seediq Bale, behind the scenes content. Accessed 30 March 2017:

https://www.youtube.com/watch?v=B6qQq1yzVOQ

120 Berber Bevernage, History, Memory, and State-Sponsored Violence: Time and Justice, Routledge Approaches to History (Routledge: 2013), 15 
discusses how the truth commission provoked the 'Madres de Plaza de Mayo' protests, which were led by the mothers of victims of state-sponsored violence. ${ }^{121}$ Bevernage contrasts the time-as-irreversible ("the past is past") attitude that the transitional governmental adopted, with the Madres conception of the past as "lingering-in-thepresent." The struggle between the Madres and the transitional government hinged on this different attitude towards the disappeared. The Madres seemingly refused to acknowledge the death of their almost certainly dead children, and instead referred to them in the present tense, and celebrated their birthdays every year.

In 1995, then President Menem came under domestic and international pressure to publish lists of names of those who perished under the state's terror campaign. The Madres, however, protested this idea because according to them it represented a "government strategy aiming to 'finish the whole issue of the desaparecidos, transforming them into dead people." In 1999, the Madres also protested the plan to build a memorial park in Bueno Aires for similar reasons: they opposed relegating the disappeared to "oblivion," and advocated for an active or "fertile memory" that fed the "hunger for justice." ${ }^{122}$ From the Madres' perspective, "oblivion" gave the government immunity. Government officials tried to protect themselves and many of those in the military who were involved in the Dirty War for political reasons, and wanted to proceed with a kind of "forgetting" of the past by finalizing the desaparecidos' death. This desire to "forget” on a societal level is exemplified by General Martin Balza's 1995 apology statement with regard to the armed forces' Dirty War crimes, in which he claimed that

\footnotetext{
${ }^{121}$ These victims were known as "desaparecidos," the Spanish name for victims who were "disappeared" by government forces during the war. Similar "disappearances" occurred during the Kuomintang's period of martial law.

${ }^{122}$ Bevernage, History, Memory, and State-Sponsored Violence, 37
} 
"if we do not succeed in closing the wounds and in performing the labor of mourning, we will not have a future." 123

Of course, the Madres not only rejected Balza's attempt to quiet truth seekers who continued to demand justice for the desaparecidos, but they also refused to adopt the traditional task of mourning. In his introduction, Bevernage points out that there is a close relation between the "politics of time" and the project of "nation building."124 Benedict Anderson, according to Bevernage, argues that the genesis of modern nations can't be understood without taking into account the development of a concept of "simultaneity." The nation relies on individual imagination of other nationals coexisting in a simultaneous time. Nations are thus perceived as solid communities moving through historical time. It is this project of simultaneity, Bevernage suggests, that is threatened by abundant memories of atrocious pasts. The threat lies not in that these memories evoke a divisive past, however, but that they experience this divisive past as irrevocable, and thus ever-present. Therefore the nation with a synchronized, simultaneous perception of time is helped if the past is collectively remembered as remaining apart from the present. ${ }^{125}$

According to Bevernage, an important point in these transitional governments' acts of acknowledging and apologizing for past crimes through truth commissions was their focus on restorative, not retributive, justice. ${ }^{126}$ In Chapter Two I pointed out that Lee Teng-hui's popularity in the 1990 s as a transitional president was partially due to

\footnotetext{
123 Ibid., 42

124 Ibid., 15

125 Ibid., 16

${ }^{126}$ This nonviolent type of justice was rooted in tension, for it meant to appease those demanding it, and protect the perpetrators who were affiliated with the government or military. What is "restored" is thus a trust in the legal process and good faith in the government, which hastens the population's "forgetting" of its traumatic past.
} 
the fact that he sought to confront the Kuomintang's White Terror-era crimes by personally addressing and visiting grieving families and constructing memorials. Now, I turn back Wei's work in post-democratic Taiwan. Wei's self-professed mission was to "dissolve sorrow" and "hatred" with Cape and Seediq, so I interpret the films as a kind of restorative art, as a kind of healing and meditation on traumas of the past.

Cape and Seediq are thematically concerned with multiple levels of "reconciliation." On the surface level, separate groups within the films are reconciled with each other through shared experience. A-ga and Tomoko develop a romance despite initial clashes, and A-ga himself is a symbol of "reverse urbanization." A-ga's return to Hengchun and his participation in the band not only helps Hengchun's economy, but boosts the town's reputation and reinvigorates its community. Old and young, local and foreign, urban and rural are reconciled by the conclusion of the plot. On the narrative level, the line of plot that takes place in 1945 during the de-colonization process intertwines with the present in such a way that generates, then releases upon the dramatic climax, a nostalgic longing for the past. The two-fold reconciliation has two effects: the audience is not only encouraged to ruminate on Taiwan's Japanese past and its connection to the present, but also to consider the present social circumstances and issues faced by various groups within Taiwan. The audience is presented with an image of Taiwan as essentially multicultural and ethnically diverse. But every individual also has their own personal or communal vision/motive. The film begins with interpersonal conflict that is resolved in the finale. However, it is not resolved by the uniting of identities under a common cause, or the recognition of a common essence which binds them, even though all the band members end up performing together fluidly. Rather, 
there is hard earned compromise, tolerance, and even respect between the characters, but the film doesn't take the extra step to provide a set of binding values for the group. Instead it is through individuals overcoming their own shortcomings that leads to success (and the romance between A-ga and Tomoko).

Additionally, the predominant language used in Cape is Taiwanese (Hokkien), with Japanese coming second and mandarin Chinese third. The use of Taiwanese highlights Hengchun's provinciality, for mandarin (which was only widespread after the Kuomintang arrived) is today dominant among the majority of urban and young populations. So, although Cape No.7 is not concerned with justice, the film clearly presents an alternative to the "simultaneous time" that Anderson and Bevernage associate with the nation proper. The film's use of the "lingering past," its heavy emphasis on provinciality and the diversity of ethnicity and language, inculcate a notion of Taiwanese identity that is outside of traditional Kuomintang conceptions of Taiwan as a solidly "Chinese nation."

Taking inspiration from Hayden White, I am not primarily concerned with Seediq Bale's empirical accuracy, but instead with the implications of Wei's narrative and the method of his construction of historical events for Taiwanese audiences. Ultimately, it is Wei's affirmation of the "other" that I find compelling and relevant to our consideration of present-day Taiwan's relation to colonial Taiwan. Wei reshuffled perspective in such a way that allowed him (and his audience) to explore aboriginal colonial subjectivity. Wei discovered the Musha Incident through a historical graphic novel written by Chiu Ruolong that was based on Incident and the violent struggle between the Seediq people and Japanese colonial authorities. In 2004, Wei produced a trailer based on the Musha 
Incident to show potential investors, but they were not interested at the time. In an interview, Chiu Ruo-long (who worked as the film's history and art consultant), recalled that when shown abroad, the trailer confused people due to their lack of exposure to aboriginal Taiwanese history and cultures. ${ }^{127}$

Unlike Cape, Seediq is set entirely in the historical past, but Wei did not seek simply to recount events as they occurred according to available documents. Built into Seediq's narrative are two propositions: first, that the audience reconsider Taiwan's history from the perspective of those traditionally considered an "other," specifically Taiwan's non-Han mountainous-region aborigines. The second proposes that the audience break down boundaries between colonizer-and-colonized. Explicitly and implicitly, Wei suggests that the Seediq peoples, as representatives of a colonized Taiwanese population, were not essentially different from the Japanese colonizers. The "Seediq" and "Japanese" identities in Seediq Bale overlap in some instances. Dakis Nomin, for example, is a young Seediq man who tries to adopt Japanese customs and language, and works under the Japanese as a police officer, one of the higher forms of employment an aborigine could obtain at the time. ${ }^{128}$ Kojima, a Japanese officer, also learned the Seediq language and was on friendly terms with the Seediq until his family perished during the Musha Incident. During the brutal fighting after the Musha massacre, a Japanese general expressed respect for the Seediq upon realizing that they were willing to die for honor.

\footnotetext{
${ }^{127}$ Seediq Bale, behind the scenes content. Accessed 30 March 2017: https://www.youtube.com/watch?v=B6qQq1yzVOQ\#t=ohomos ${ }_{128}$ Interestingly in Cape No.7, guitarist Rauma and his father, both members of the Rukai aborigine group, are also police officers. Not to stretch an interpretation, but perhaps this is a comment on the present aboriginal social situation. Taiwanese aborigines, especially from the mountain-dwelling groups, remain predominantly of lower socio-economic status, and are treated as disadvantaged populations. For example, minimum test scores for aborigine children for high school and college admissions are lower than that of the general population.
} 
Is Seediq a commemoration of Taiwan's aborigines? Is it a nationalistic film? Seediq implies that Mona was successful in preserving his people's honor and "tradition" in the final scene which depicts Mona leading Seediq across a rainbow path to the afterworld. Wei provides an alternative way of conceiving "Taiwanese" which is totally external to the predominant Han-Chinese classification. ${ }^{129}$ Seediq is also unique in that it encourages a mandarin-speaking audience to empathize with sets of characters who are not only ethnically separate, but who do not even speak the same language; this is an important point in Balibar and Anderson's theories, with regard to shared national identity. Although the Seediq are indeed depicted as defenders of tribal honor, and are aware of their distinct culture and heritage as opposed to the Japanese, the film does not insinuate that the Seediq were defending some abstract notion of "Taiwan." In a review of the film, historian Ian Inkster pointed out that instead of taking Seediq at face value as a proponent of "Taiwanese nationalism," viewers should consider the complex treatment of the few Chinese characters in the film. Despite the fact that Taiwan today (as was the case in 1930) is overwhelmingly Han-Chinese, and that its economic success in recent decades occurred under a nominally Chinese government, the film positions Chinese characters (who are here invariably merchants of some sort) at the border between "civilization/modernity" and "periphery/barbarism." Inkster points out that the story of the Atayal peoples and Chinese settlers goes back farther: that groups like the Atayal were designated "mountain savages" during the Japanese era precisely

129 There appear only to be a few Han-Chinese characters in the film, none of them with a significant amount of screen time. 
because they had been pushed eastward towards the mountainous center of the island as Chinese settlers dominated the plains of western Taiwan. ${ }^{130}$

Additionally, Seediq Bale is ambiguous in its treatment of aboriginal violence. The film does not celebrate aboriginal violence, committed against both the Japanese and the Seediq people themselves, for it is depicted in a graphic and difficult manner throughout the film. Wei referred to Seediq as a meditation on "civilization and barbarism," in the sense that the ostensibly "civilized" (Japanese) and "barbaric" (Seediq) groups within the films each displayed a mix of noble and savage behaviors. I would also add that the film is actually more of a portrait of the conflicts between individual, or small-group, identities within Taiwan, rather than an attempt to provide a comprehensive historical argument about the context of the Musha Incident.

So, what is the Musha Incident for present-day Taiwanese, given that the film was obviously meant to be viewed primarily by non-aborigines? Do Wei's films seek to educate public's "historical imagination?" Seediq is not a work of professional history, but perhaps it succeeds as a commemoration of a group of Taiwan's aborigines. I think Seediq's value for its Taiwanese audience is exemplified by its nuanced treatment of aboriginal police officer Dakis Nomin's cultural quandary. Dakis inhabits a liminal space: on the one hand, he believes in order and progress (insofar as progress entails technological modernization concurrent with increasing state presence), and wants to leave behind the tribal life, yet on the other he recognizes that he will never be fully accepted by the Japanese. As a post-colonial, democratized country, Taiwan also occupies a liminal space on the world stage: between nation and "province" of China. 
The people of Taiwan today live under a state that was once mired in a conflict with the People's Republic of China, but has long since forsaken its cause in practical terms. If, as Renan held, nations were forged out of conquest and held together by a sense of shared suffering, then what do we make of Taiwan's unfinished conquest under the Kuomintang? The lack of a mutually-acknowledged political resolution of the Chinese civil war is the greatest influencing factor in Taiwan's current political status. Instead of a resolution by conflict, the Kuomintang instead morphed into a popular government, and elections were held despite the remaining political problem with China. Although resolution may seem impossible from a political and international relations standpoint, it can be imagined handily in fictional representations of the past. As Wei himself stated, his films seek to "resolve" past sufferings, and it is clear that cultural confusion and conflict, key themes of Taiwan's modern history, are key themes in his films as well. ${ }^{131}$ I believe the image of Taiwan Wei's films present embodies a postnational character, in that it is a rejection of a united cultural identity and heritage. The films show that "Taiwanese life" can be classified in so many ways that that the designation of a Taiwanese nationalism is almost meaningless. Wei's Taiwan-centered perspective instead explores regional, linguistic, and ethnic differences within the space of Taiwan, quite divorced from Kuomintang-PRC politics of the late twentieth-century. Perhaps Wei's exploration of regional and local identities through film resonates with audiences in contemporary Taiwan in a way that "national" identity simply cannot.

\footnotetext{
${ }^{131}$ Kano, a 2013 film that Wei produced and co-wrote, is another example. The film tells the story of a multi-racial baseball team (composed of aboriginal, Chinese, and Japanese members) in Japanese Taiwan. The underdog team, Kano, overcomes various trials to represent Taiwan in 1931 at the Japanese National High School Baseball Championships in Nishinomiya.
} 


\section{Conclusion}

A September 2011 newspaper ran a story that “revised” Mona Rudao's legacy visà-vis Seediq Bale when the film was still hot in the box office. In an interview with several Atayal representatives and elders in Heping District of Taichung County, one elder recounted that his father told him a story of Mona Rudao's collaboration with Japanese authorities, as part of the colonial authority's “fighting barbarians with barbarians" strategy in early twentieth century. In order to help bring this elder's village in line (as it had resisted Japanese rule up to then), Mona Rudao travelled from Nantou County and conducted a raid with Japanese forces while the village's men were out hunting. Mona's punitive force killed an estimated twenty-six people, predominantly women and children. The article compares and contrasts this account with that of historians and other Atayal representatives, and even includes an interview with the artistic and historical consultant of Seediq, Chiu Ruo-long. Chiu admitted that infighting among aboriginal groups was common during the colonial era, as Japanese forces played rival groups against each other. Despite the fact that Seediq seemed to portray Mona Rudao in a heroic light, the article ends on a conciliatory note by pointing out that the film had achieved its primary goal: it brought much needed public attention to Taiwan's aboriginal population and its history. ${ }^{132}$

How do we reconcile different "memories" and opinions on the past and present (especially in the form of oral histories)? And what does a historian actually do in the act of recounting the past? The historian describes (what happened), she explains (why it

\footnotetext{
${ }_{132}$ Atayal Elders, interview by Kuo Rui-chun, Chen Tsing-te, Chen Fang-ying, "Twenty-six Women and Children Murdered: 'Mona Rudao was Not a Hero," Apple Daily, 12 Septermber 2012, Accessed 30 March 2017 at: http://www.appledaily.com.tw/appledaily/article/headline/20110912/33662442
} 
happened: causes and/or purposes), she justifies it (evidentiary basis for descriptive and explanatory claims), and she offers an interpretation of it (the past's significance for us in the present). In "Essentially Narrative Explanations,” philosopher Paul A. Roth argues against C.G. Hempel's (1942) logical-empiricist stance with regard to history qua "science.” Hempel’s 1942 article “The Function of General Laws of History” expressed the view that history should be a deductive-nomological science, a view also designated as the "covering law" model. Hempel's covering law model emulated "hard" science methodology in its bias for the explanatory power of general laws rather than particular descriptions and explanations. Roth points out that this model's bias toward "universalizing" explanations, while not cutting-edge in the theory of history, is certainly still "entrenched" in the "philosophical consciousness."133 Roth counters by suggesting that narrative (descriptive) explanations are uniquely suited to answer certain explanatory questions.

In his explication, Roth points to intellectual historian Allan Megill's analysis of Fernand Braudel's The Mediterranean and the Mediterranean World in the Age of Phillip II. Megill holds that narratives "seem to offer primarily recountings," or detailed “descriptions of a chosen subject over time."134 Braudel's Mediterranean seems to lack a defining feature of narrative: a focus on a single subject's development over time in a way that explains why the subject was different between temporal points A and B. However, The Mediterranean, Roth explains via Megill, is nonetheless a narrative history because it redefined character and setting ("existents," or things that are, as

\footnotetext{
${ }^{133}$ Paul A. Roth, "Essentially narrative explanations," Studies in History and Philosophy of Science Part A (Elsevier: 2016), 1. Accessed 1 April 2017 at: http://www.sciencedirect.com/science/article/pii/So039368117300754 134 Ibid., 4
} 
opposed to "events," or things that occur) in such a way that "The Mediterranean" as a geological entity became a chief actor in the plot laid out under Braudel's pen. Therefore Mediterranean was indeed a narrative, though more "an anatomizing narrative of character" than a "sequential narrative of action." 135 Roth uses the Braudel example as one of several in demonstrating the importance of particular description in historical explanations. Roth's argument leads him to conclude that a universal history is impossible, because narratives do not aggregate. Rather, narrative explanations must be evaluated comparatively, against "competing narratives." 136

It is with this frame of mind that I review the significance of my primary data set. In this thesis I have combined detailed explications of the works and their contexts with a framework that allows us to view the works collectively as historical documents. I have shown that these "documents" provide interesting interpretations of Taiwanese life in the colonial past, and that when viewed collectively they allow us to access the problem of national identity in Taiwan from a fresh perspective. In a way, the works perform a constructive historical task that, paradoxically, has proven to be difficult in the realm of political history proper. That is, these fictions do not settle at a point of political nonreconciliation between Taiwan and China with regards to the question of Taiwan's ethnicity and the status of its nationhood, but rather utilize the past in an effort to complicate and question the very notion of "nationhood" with regard to Taiwan.

Common to each work is the understanding that Taiwan (whether in the Japanese or Kuomintang eras, or the present) is a setting, and that the people that

${ }_{135}$ Allan Megill. Recounting the Past: "Description," Explanation, and Narrative in Historiography. The American Historical Review, Volume 94, Issue 3 (Jun., 1989), 646

${ }_{136}$ Paul A. Roth, "Essentially narrative explanations," Studies in History and Philosophy of Science Part A (Elsevier: 2016), 8. Accessed 1 April 2017 at:

http://www.sciencedirect.com/science/article/pii/So039368117300754 
inhabit it are characters, and that events occurred which affected the characters and setting. My analysis has led me to conclude that the works do not take the extra step to merge the two sets of "existents" (to use Megill's terminology). That is, characters do not perceive an essential link between themselves and the general setting of "Taiwan" soil in a way that allows for "Taiwan nationalism." Rather, the pre-democracy pieces communicate a sense of cultural confusion and loss through Hu Taiming and the Lin family without portraying this confusion and loss as a cause for national unity in the face of competing identities and political entities (the Japanese and Kuomintang). In other words, there is oppression and there are hints at resistance, but there is no cohesiveness, no synthesis out of hardship that creates a national whole that can shrug off oppressors, literally or symbolically. Orphan ends with Taiming's madness and disappearance, while City ends with a shot of the broken Lin family, in which the brothers have either died, disappeared, or become insane.

Wei Te-sheng's films build on these themes of loss and confusion (rather, the films begin with characters defined by loss and confusion), but differ in several important ways. They provide more conclusive, cathartic endings, and their narratives feature entirely different sets of characters compared to their artistic predecessors. In Seediq Bale, for example, the audience is exposed to images of "living" people of historical Taiwan who differ drastically in ethnic, spiritual, and linguistic terms. The Seediq are also interesting because, of all the characters in these works, they alone tend to express an immaterial connection to their land (specifically, ancestral hunting grounds), but this land strictly denotes a small region in the mountains of Nantou. Because the Seediq are isolated from Han influence, and seem only moved to fight for 
their land and resources when intruded upon by the Japanese and other Atayal, they cannot plausibly represent a "Taiwan nationalism." Interestingly, one of the central conflicts in Cape is one between the local-rural (represented by the people of Hengchun, and town representatives) and the globalizing-urban (represented by the Japanese band, the hotel owner, Tomoko, and the modeling agency). A-ga, the protagonist, is located between the two worlds at the beginning of the film, but he curses Taipei city and rides south back to Hengchun. I think Wei's films therefore provide a satisfying answer to the inconclusiveness of Orphan and City, by forsaking the "big" obstacles that plagued Taiming and the Lin family (maneuvering between Chinese culture, Japanese culture, Taiwanese nation, and Chinese nation) in favor of the regional, or even micro-local.

Perhaps the different portrayals of Taiwanese life in pre-and-post democracy historical fiction can be attributed to the strange nature of Taiwan's democratic transition. After all, the Kuomintang under Chiang Ching-kuo and Lee Teng-hui, as a symbol of "Chinese" Taiwan, had willingly forsaken single party rule for a popular government. Democratic Taiwan thus wasn't “won” unilaterally through violent upheaval of one group by another, but reached through gradual, albeit difficult, compromise. Moreover, the Kuomintang itself has "Taiwanized" since 1949, with Taiwan-native Lee Teng-hui (who speaks Japanese more adeptly than Mandarin) as exemplary of this cultural transition within the party. Taiwan's population itself has also become more aware of its own diverse present and past in recent years, in large part due to the influence of films such as Cape and Seediq.

Wei, along with most Taiwanese living today, has lived under both a single-party regime and a popular democracy. Taiwanese have also lived with constant political 
pressure from the PRC, and Taiwan's sovereignty has been questioned internationally, from flag bearing at the Olympics to severed diplomatic ties and revoked U.N. membership. Because of this atmosphere of uncertainty, I think present day artists like Wei (implicitly or explicitly) try out various "looks" of nationalism, or interrogate different ideas of nation, through their depictions of historical Taiwan. The postnational character of Cape and Seediq that I've picked up on may be one such interrogation of the idea of nation.

In writing this thesis I have joined a growing community of scholars who investigate Taiwanese art and history in relation to the problem of national identity. Several of these scholars, including Jason Ho Ka-hang, have also identified postnational aspects of recent films and literature in Taiwan. In "Enlivening New Taiwan Cinema: In Search of Taiwaneseness and the Postnational” Ho characterized Cape No. 7 as a work imbued with a post-national character, as "something less nationalistic/political than humanistic/personalized in the form of belonging to a community." ${ }^{137} \mathrm{He}$ further states that the idea of the post-national "does not simply go beyond the national: it dialogues with nationalism and reacts critically to globalization." ${ }^{138}$ Mary Goodwin, a professor of English based in Taiwan, has also recently made a convincing argument about the how the "post-national" TaiwaneseAmerican protagonists of several English-language novels set in Taiwan (Francie Lin's The Foreigner and Julie Wu's The Third Son) parallels modern Taiwan's uncertain cultural and political situation. In citing the work of Habermas and Appadurai, Goodwin

\footnotetext{
137 Jason Ho Ka-hang, "Enlivening new Taiwan Cinema: In Search of Taiwaneseness and the Postnational," Tresspassing Journal: An Online Journal of Trespassing Art, Science, and Philosophy (Trespassing Journal: 2012), 63. Accessed 3 April 2017 at: http://trespassingjournal.com/?page id=390 ${ }^{138}$ Ibid, 64
} 
points out that many contemporary scholars perceive the nation-states and national identifications as soon to be obsolete, replaced instead by "supranational and global entities such as multinational corporations and internationalized financial markets," in the context of increased global migration. 139

As part of my research for this thesis, I travelled to Nanwang village in Taitung County (located on the southeastern coast of Taiwan) in December 2016. Nanwang and its surrounding communities are populated mostly by members of the Puyuma aboriginal group. The Puyuma, along with most aboriginal tribes in central and eastern Taiwan, were historically "mountain" aborigines. I was invited to participate in the Nanwang Puyuma's annual year-end hunting ceremony, which took place in a campsite in the mountains, and I spent my time in the camp gathering interviews from Puyuma elders in order to learn more about the tribe's history. ${ }^{140}$ One elder told a story that particularly fascinated me. It explained the historical roots of one of the tribe's modern rituals, in which young Puyuma men gathered grass and tied it into sizeable bundles, which they then tossed in all directions out of the campsite.

As I listened, stinging ash from the many meat-smoking pyres in the camp blew onto us, permeating our clothes and food, and coaxing tears from our eyes. The ritual, it turned out, was meant to ward off evil: the grass bundles substituted for the heads of slain enemies. Because the Puyuma (like most of Taiwan's aboriginal tribes) were once

\footnotetext{
139 Mary Goodwin, "Postnational Homelands: Migration and memory in two novels of Taiwan." Neohelicon, AHCI: 19 October 2016. 3-4. Accessed 3 April 2017 at: https://link.springer.com/article/10.1007/s11059-016-0360-y 140 The Puyuma, like most of Taiwan's aborigine groups, do not have a written language. Ethnographies which address the Nanwang Puyuma's history have been written in both Chinese and English. For an ethnography of the Puyuma, see Josiane Cauquelin, The Aborigines of Taiwan: The Puyuma, from Headhunting to the Modern World (RoutledgeCurzon: New York, 2004).
} 
headhunters, these threats historically came in the form of night raids from rival tribes on unsuspecting camps and villages. After one particularly devastating attack on the village which left many elders dead and their heads taken as trophies, the Nanwang Puyuma began to toss the severed heads of captured enemies outside their camps to deter enemies from attacking. The elders pointed out that after the Japanese era headhunting was forbidden, and today grass bundles fill the role in the auspicious rite.

Like the grass "heads," the year-end hunting ceremony itself carries a different meaning today than it used to. Young people increasingly leave the village for jobs in big cities around Taiwan, and while it was once held in reverence of spirits that ensured abundant game and harvests, the ceremony is now seen as a way to gather the scattered Puyuma community together again, to "remind" the young of their Puyuma heritage and identity. This identity is reinforced through inter-generational socializing and storytelling, which is an important way of preserving knowledge of Puyuma history due to their lack of written language. In listening to the elders' stories, I realized that although I've lived in Taiwan for almost twenty years, I actually knew very little about how others who shared my "homeland" lived outside of urban Taipei. Before this visit to Nanwang, I couldn't imagine young Taiwanese men hunting for their food, cleaning carcasses, and providing for their communities; most of my peers growing up could barely manage making a bowl of instant noodles. I realized that "Taiwan" was a much more diverse place than I had previously imagined, and that vastly different "histories" and identities are associated with (and exist on) this island. Filmmakers such as Wei Te-sheng realize this, and have brought public attention to aboriginal and Japanese-era history, and by extension the aborigines' present day social circumstances. 
Now, historians of Taiwan can follow suit and look outside the Taiwan-China dynamic. Perhaps instead of addressing Taiwan as a semi-national state stuck in a "dead-end" struggle with China over sovereignty, historians of Taiwan can look inward, to the local and grassroots level, to question the adequacy of traditional categories like "Han-Chinese," "nation-state," and "national identity." I believe scholars around the world can also learn from the historical complexity of Taiwan's situation to bring more nuanced perspectives to the topics of national identity and international relations. 


\section{Bibliography}

\section{Primary Sources}

\section{Books}

Yosaburo, Takekoshi , Japanese Rule in Formosa, with a preface by Baron Shimpei Goto, trans. George Braithwaite. Longmans, Green, and Co., 1907.

Davidson, James Wheeler, The island of Formosa, past and present. History, people, resources, and commercial prospects. Tea, camphor, sugar, gold, coal, sulphur, economical plants, and other productions. London and New York: Macmillan \& co.; Yokohama [etc.] Kelly \& Walsh, ld, 1903.

Wu Zhuoliu, The Fig Tree: Memoirs of a Taiwanese Patriot, trans. Duncan Hunter. Authorhouse: 2002.

Wu Zhuoliu, Orphan of Asia: a Novel, trans. Ioannis Mentzas. Durham: Duke University Press, 2004.

\section{Films}

A City of Sadness, directed by Hsiao-Hsien Ho. 1989. 3-H Films: Taiwan, 1989. DVD.

Cape No. 7, directed by Wei Te-sheng. 2008. Buena Vista: Taiwan, 2008. DVD.

Warriors of the Rainbow: Seediq Bale, directed by Wei Te-sheng. 2011. Vie Vision Pictures: Taiwan, 2011. DVD.

\section{Secondary Sources}

Ankersmit, F. R., "In Praise of Subjectivity." Introduction to Historical Representation. Palo Alto, CA: Stanford University Press, 2001. 3-75. 
Balibar, Etienne, Wallerstein, Immanuel, Historiography: Critical Concepts in Historical Studies, trans. Chris Turner. Ed. Robert M. Burns. Routledge, London and New York: 2006.

Balibar, Etienne, Wallerstein, Immanuel, Race, Nation, Class: Ambiguous Identities. Radical Thinkers. Verso: 2011.

Berber Bevernage, History, Memory, and State-Sponsored Violence: Time and Justice. Routledge Approaches to History. Routledge: 2013.

Blundell, David, ed., Austronesian Taiwan, Linguistics, History, Ethnology, and Prehistory. The Regents of the University of California, 2000.

Brown, Melissa J., Is Taiwan Chinese? The Impact of Culture, Power, and Migration on Changing Identities. University of California Press, 2004.

Cauquelin, Josiane, The Aborigines of Taiwan, The Puyuma: from Headhunting to the Modern World. RoutledgeCurzon, 2004.

Chang, Yvonne Sung-sheng, Literary Culture in Taiwan: Martial Law to Market Law. Columbia University Press, 2004.

Chang, Yvonne Sung-sheng, Modernism and The Nativist Resistance. Duke University Press, 1993.

Chen, C.M., Chuang Y.C., Huang S.M., ed., Ethnicity in Taiwan, Social, Historical, and Cultural Perspectives. Institute of Ethnology, Academia Sinica, 1994.

Chen, Rou-lan, Beyond National Identity in Taiwan: A Multidimensional and Evolutionary Conceptualization. Asian Survey, Vol. 52, Number 5. 845-871, Regents of the University of California, 2012.

Chen, Rou-lan, Reconstructed nationalism in Taiwan: a politicized and economically driven identity. Nations and Nationalism Vol. 20, Number 3, 2014. 523-545. 
Ching, Leo T.S. Becoming "Japanese": Colonial Taiwan and The Politics of Identity Formation. University of California Press, 2001.

Conrad, Joseph, Heart of Darkness: A Norton Critical Edition, $4^{\text {th }}$ ed., ed. Paul B. Armstrong. W.W. Norton, 2006.

Copper, James F., Taiwan, Nation-State or Province? 6th ed. Westview Press, 2013.

Corcuff, Stephane, Memories of the Future: National Identity Issues and the Search for a New Taiwan. M.E. Sharpe Inc., 2002.

Davison, Gary, A Short History of Taiwan, the Case for Independence. Praegar Publishers, 2003.

John W. Dower. Embracing Defeat: Japan in the Wake of World War Two. W.W. Norton \& Company, 1999. 32-39.

Driscoll, Mark, Absolute Erotic, Absolute Grotesque: The Living, Dead, and Undead in Japan's Imperialism, 1895-1945. Duke University Press, 2010.

Ebrey, Patricia, "Surnames and Han Chinese Identity," in Negotiating Ethnicities in China and Taiwan, ed. Melissa J. Brown, University of California Berkeley Institute of East Asian Studies, 1996.

Edmonds, Richard Louis, Goldstein Steven M., Taiwan in the Twentieth Century: A Retrospective View. Cambridge University Press, 2001.

Faure, David, ed., In Search of the Hunters and their Tribes, Studies in the History and Culture of the Taiwan Indigenous People, Shung Ye Museum of Formosan Aborigines. SMC Publishing Inc., 2001.

Faurot, Jeannette L., Chinese Fiction from Taiwan: Critical Perspectives. Indiana University Press, 1980. 
Foucault Michel, "Society Must Be Defended, Lectures at the College De France, 1975-76" ed. Marlo Bertani and Alessandro Fontana, trans. David Macey. Picador: New York, 2003.

Gold, Thomas B., "Civil Society and Taiwan's Quest for Identity," in Cultural Change in Post-war Taiwan, ed. Steven Harrell and Junjie Huang. Boulder, Co.: Westview Press, 1994.

Goodwin, Mary, "Postnational homelands: Migration and memory in two novels of Taiwan," Neohelicon, AHCI, October 2016.

Philips, Steven E., Between Assimilation and Independence: The Taiwanese Encounter Nationalist China, 1945-1950. Stanford University Press, 2003.

Harrison, Mark, Legitimacy, Meaning, and Knowledge in the Making of Taiwanese Identity. Palgrave MacMillan, 2006.

Hsu, Chien-Jung, The Construction of National Identity in Taiwan's Media, 1896-2012. Brill, 2014.

Hicks, George, The Comfort Women, Japan's Brutal Regime of Enforced Prostitution in the Second World War, W.W. Norton \& Co., 1994.

Inkster, Ian, “'Seediq Bale’ and Pride in Taiwan,” Taipei Times, 8 March 2012.

Ka, Chih-ming, Japanese colonialism in Taiwan: land tenure, development, and dependency, 1895-1945. Westview Press, 1995

Katz, Paul R., When Valleys Turned Blood Red: The Ta-pa-ni Incident in Colonial Taiwan. University of Hawai'i Press, 2005.

Kennedy, Malcom, The Estrangement of Great Britain and Japan, 1917-35. (Los Angeles: University of California Press, 1969), 56-57. 
Kerr, George H., Formosa, Licensed Revolution and the Home Rule Movement 18951945. The University Press of Hawai'i, 1974.

Faye Yuan Kleeman, Under an Imperial Sun: Japanese Colonial Literature of Taiwan and the South, (University of Hawai'i Press: 2001), 79-81.

Lin, April C. J., Keating, Jerome F., Island in the Stream: A Quick Case Study of Taiwan's Complex History, 3rd Ed., SMC Publishing Inc., 2005.

Lin, Syaru Shirley, Taiwan's China Dilemma, Contested Identities and Multiple Interests in Taiwan's Cross-Strait Economic Policy. Stanford University Press, 2016

Megill, Allan, Recounting the Past: “Description,” Explanation, and Narrative in Historiography. The American Historical Review, Volume 94, Issue 3 (Jun., 1989).

Morris, Andrew D., "Taiwan's History: An Introduction" The Minor Arts of Daily Life: Popular Culture in Taiwan. Honolulu, HI: University of Hawai'i Press, 2004. Available at: http://works.bepress.com/admorris/6/

Morris, Andrew D., Savages, Traitors, Budweiser, and a History of Globalization and Baseball in Taiwan, Presented to the Conference on Globalization and Sport in Historical Context at University of California: San Diego, March 2005.

Munsterhjelm, Mark, Living Dead in the Pacific, Racism and Sovereignty in Genetics Research on Taiwan Aborigines. University of British Columbia Press, 2014.

Nora, Pierre, Between Memory and History: Les Lieux de Mémoire, Representations, No. 26, Special Issue: Memory and Counter-Memory, 7-24, Spring 1989.

Ernest Renan, "What is a Nation?," text of a conference delivered at the Sorbonne on March 11th, 1882, in Ernest Renan, “Qu'est-ce qu'une nation?" trans. Ethan Rundell. Presses-Pocket: Paris, 1992. 
Rubinstein, Murray A., ed. Taiwan: A New History. East Gate Books, Armonk, New York and London: M. E. Sharpe, 1999 (expanded edition, 2007).

Simon, Scott, Tanners of Taiwan: Life Strategies and National Culture. Westview Press, 2005.

Shepherd, John R., Statecraft and Political Economy on the Taiwan Frontier, 160o180o. Stanford University Press, 1993.

Tai, Eika, Intermarriage and imperial subject formation in colonial Taiwan: Shoji Soichi’s Chin-fujin, Inter-Asia Cultural Studies, Routledge, 2014 Vol. 15, No. 4, 513-531.

Tang Xiaobing, "On the Concept of Taiwan Literature," in Writing Taiwan: A New Literary History, ed. David Der-wei Wang and Carlos Rojas. Duke University Press, 2007.

Teng, Emma Jinhua, Taiwan's Imagined Geography: Chinese Colonial Travel Writing and Pictures, 1683-1895. Harvard University Press, 2004.

White, Hayden. "The Value of Narrativity in the Representation of Reality." Critical Inquiry 7, no. 1 (1980): 5-27. 